\title{
El atrio de la Catedral de León. Edificación, polémica y reclamaciones de una obra singular de finales del siglo XVIII
}

\author{
Emilio MORAIS VALLEJO \\ Universidad de León \\ A la memoria de Fernando Galván Freile, \\ compañero y amigo, que nos dejó demasiado pronto
}

\begin{abstract}
RESUMEN. A finales del siglo XVIII el cabildo de la catedral de León decidió sustituir el viejo pretil que cerraba el atrio por otro nuevo más artístico. El encargado de realizarlo fue el arquitecto Fernando Sánchez Pertejo, quien proyectó un cierre con rejería para este espacio singular. La construcción estuvo plagada de polémicas, unas artísticas y otras técnicas, en las que tuvo que intervenir la Real Academia de Bellas Artes de San Fernando. La obra es el resultado de una concepción artística finisecular, que quiere abandonar la tradición y entrar en la modernidad.

Palabras clave: Atrio, catedral de León, Fernando Sánchez Pertejo, rejería, Real Academia de Bellas Artes de San Fernando, restauración.
\end{abstract}

ABSTRACT. At the end of the eighteenth century the chapter of Leon's cathedral decided to replace the old parapet that closed the atrium by a new one more artistic. The architect Fernando Pertejo Sanchez projected an enclosed by iron railings for this singular space. The construction was plagued of controversy, some artistic and other techniques, in which it had to take part the Real Academia de Bellas Artes de San Fernando. The work is a finisecular artistic conception, who wants to abandon tradition and to enter in the modernity.

Key words: Atrium, cathedral of Leon, Fernando Sánchez Pertejo, iron railing, Real Academia de Bellas Artes de San Fernando, restoration.

Delante de las fachadas meridional y occidental de la catedral de León se despliega un amplio espacio enlosado con grandes piedras, elevado sobre el nivel que tiene el piso de la calle y delimitado por un cierre hecho con verjas de hierro y pilares de piedra. De esta manera se separa y aísla al edificio religioso del entorno civil que le rodea, al tiempo que demarca de forma explícita el territorio que está bajo la jurisdicción catedralicia (Lám. 1). Este andén ha sido denominado desde su origen, lo mismo en la documentación que en el lenguaje popular, como el Atrio de la Catedral, y sabemos que ha existido desde la Edad Media, aunque con distinta configuración como veremos más adelante, por lo que podemos presumir que fue concebido al tiem- 
po que se levantaba la catedral gótica. Semejante plan resulta original ya que no es frecuente en las catedrales españolas, y menos aún en las góticas, que suelen levantarse próximas a los edificios circundantes sin especiales barreras divisorias, con el deseo de integrar plenamente al templo en el ambiente urbano donde se ubica. Los grandes edificios religiosos siempre han buscando la proximidad del ciudadano para invitarle a ser fiel; sólo en las entradas, por lógicos problemas de seguridad, solía colocarse algún tipo de barrera protectora para impedir el paso a los intrusos, pero no era habitual dejar un amplio espacio vacío y cerrado en derredor.

La zona indicada se encuentra desembarazada y libre de cualquier elemento que oculte parcialmente o desfigure la silueta del primer templo de la diócesis leonesa. De esta manera se mantiene en esta parte apartado del caserío circundante y su visión meridional está completamente despejada para los viandantes, ofreciendo una perspectiva diáfana del edificio gótico. Al parecer, esto siempre ha sido así, pues por este lugar discurría desde el principio urbano de León una de las principales calles de la ciudad, heredera directa de la Vía principalis romana, la cual unía en perfecta línea recta trazada de este a oeste la Porta principalis sinistra (denominada Puerta Obispo desde la Edad Media) con la entrada más occidental de la muralla, la Porta principalis dextra (también conocida como Porta Cauriense); pues bien, el primer tramo de dicha calle siempre mantuvo franco su lateral septentrional, para mayor lustre del templo catedralicio, mientras que en el otro se levantaba el palacio episcopal, permitiéndose así la visión directa entre ambas sedes episcopales sin ningún tipo de obstáculo visual.

El esquema no se repite en los otros frentes de la catedral, donde estancias anejas al complejo religioso como el claustro, la monumental librería o la sacristía, permanecen adosadas a sus paredes; incluso en otros tiempos sobre algunos muros apoyaban casas particulares, alterando de esta forma el contorno del edificio.

Tenemos constancia documental de que en un principio el atrio era más pequeño de lo que es en la actualidad. En efecto, entre el límite de la portada sur del crucero y la cabecera estaban las dependencias llamadas "el Tesoro" y "la Audiencia”, y más allá el pasadizo de Puerta Obispo, edificado sobre la antigua muralla romana de la ciudad, para comunicar directamente la seo con el frontero palacio episcopal, lo que reducía considerablemente la dimensión del andén en este lateral ${ }^{1}$. Todos estos elementos fueron derribados con motivo de la restauración historicista iniciada a finales del siglo XIX, debido al decidido afán de los arquitectos de la época por aislar la catedral y devolverla el pretendido aspecto prístino que suponían debió tener en el gótico ${ }^{2}$.

El documento más antiguo conocido en el que aparece representado el atrio con su primitiva configuración se guarda en el Archivo General de Simancas ${ }^{3}$. Es un dibujo

\footnotetext{
${ }^{1}$ Estas dependencias han sido analizadas por varios autores a partir de los planos realizados por DEMETRIO DE LOS RíOS y las indicaciones recogidas en su libro La catedral de León. Monografía, Madrid, 1895. Véase por ejemplo, W. MERINO, Arquitectura hispano flamenca en León, León, 1974, pp. 40-46; J. RIVERA BLANCO, Historia de las restauraciones de la catedral de León, Valladolid, 1993, pp. 111-118; I. GONZÁLEZVARAS, La catedral de León. Historia y restauración, León, 1993, pp. 459-478; E. CARRERO SANTAMARÍA, Santa María de Regla de León. La catedral medieval y sus alrededores, León, 2004, pp. 119-128.

${ }^{2}$ Sobre la restauración de la catedral véase principalmente, J. RIVERA BLANCO, Historia de las restauraciones...; I. GONZÁLEZ-VARAS, op. cit.

${ }^{3}$ Archivo General de Simancas, Mapas, Planos y Diseños, XXXVIII- 98 Casas y Sitios Reales, leg. 13, fol. 59. El dibujo ha sido analizado por M. D. CAMPOS SÁNCHEZ-BORDONA, "Diseño de la planta de la catedral de León realizado en 1514", Archivo Español de Arte, no 252, 1990, pp. 640-646. También hacen referen-
} 
torpe y rudimentario realizado en el año $1514^{4}$, que parece más un apunte tomado del natural que un verdadero plano terminado con pretensiones de exactitud técnica, ya que no está a escala, ni los elementos que forman la totalidad del edificio están proporcionados entre sí. No obstante, resulta de suma utilidad para conocer a grandes rasgos la planta de la catedral en los inicios del siglo XVI ya que están indicados los distintos espacios y dependencias que la componían en aquella época, con sus dimensiones expresadas en pies. En él comprobamos que en aquellos momentos el atrio corría por toda la fachada occidental y parte de la meridional, justo hasta pasar la portada sur del crucero, donde se puede apreciar claramente un muro perpendicular a la catedral, que se corresponde con el extremo de la citada Audiencia y suponía el límite oriental del ándito (Lám. 2).

Un segundo dibujo, elaborado a finales del siglo XVI y que no muestra demasiada habilidad por parte del delineante ${ }^{5}$, representa una insólita doble visión de la catedral leonesa y los edificios circundantes, que, entre otras cuestiones de interés, proporciona detalles valiosos para el conocimiento de la antigua cerca del atrio catedralicio ${ }^{6}$ (Lám. 3). Gracias a él podemos

cia al dibujo C. Álvarez TeráN, Archivo General de Simancas. Catálogo de mapas. planos y dibujos. Años 1503-1805, Valladolid, 1980, p. 618; J. RIVERA, Arquitectura de la segunda mitad del siglo XVI en León, León, 1982 , p. 70.

${ }^{4}$ C. Álvarez Terán, op. cit., p. 619, fijó la fecha del dibujo atendiendo a las anotaciones que hay en el dorso del plano, donde aparece escrito: Recibo de Diego de Lequeitio y de Ochoa de Landa, medidas de la yglesia de Leon, así como el asiento de unos recibos, datándose uno de ellos el 4 de diciembre de 1514.

${ }^{5}$ D. DE LOS Ríos, op. cit., t. II, p. 35, dice que ...fue ejecutado por un artista novel hasta el candor.

6 Archivo de la Catedral de León (desde aquí ACL), Retrato de la iglesia de León con su sitio a la plaza y casas que se hizo para informar de la verdad a los Ilmos. Cardenales de la Congregación de los Obispos, letra f, leg. $\mathrm{n}^{\mathrm{o}} 4$. constatar que el cierre consistía en un murete no muy alto, reforzado a intervalos regulares con pilares que sobrepasaban la altura del pretil y estaban decorados en la cúspide con pequeñas esculturas. Pero quizá el dato más revelador que nos proporciona la imagen se refiere a la primera intervención importante que se hizo en el atrio y que alteró su fisonomía original. El cabildo decidió, por un acuerdo capitular de 1566, realizar una nueva fuente en la plaza de $\mathrm{N}^{\mathrm{a}}$ Señora de Regla que se abre delante de la fachada occidental de la catedral, en contra de la voluntad del Ayuntamiento leonés que mantenía serias discrepancias con los representantes eclesiásticos acerca de la situación de las fuentes públicas. La idea de los capitulares fue sustituir al antiguo caño hasta entonces en uso, que abastecía de agua a los vecinos de la zona y era además uno de los principales puntos de distribución de la red de transporte de aguas por la ciudad, por una fuente monumental ubicada en el ángulo sur occidental del atrio. La polémica entre Ayuntamiento y Cabildo era de hondo calado, pues no sólo ponía en cuestión el trazado de las cañerías por la ciudad, sino que incluso con su actuación se dilucidaba el carácter civil o religioso de la principal plaza urbana de León en aquellos momentos, así como la propia ordenación y fisonomía de la misma ${ }^{7}$.

Según parece, a la vista de la ilustración conservada, la cual por desgracia no presta tanta atención a los detalles como nos gustaría, la fuente constaba de un gran pilón rectangular, cuyo lado posterior estaba en línea con el cierre del atrio, de manera que en realidad se extendía hacia la plaza ocupando territorio civil. Estaba flanqueado

\footnotetext{
${ }^{7}$ Sobre el traslado del caño y la disputa entre Ayuntamiento y Cabildo, véase M. D. CAMPOS SÁNCHEZ-BORdONA y M. L. PEREIRAS FERNÁNDEZ, Iglesia y ciudad, su papel en la configuración urbana de León: Las plazas de San Isidoro y Regla, León, 2005, pp. 308,347 y 349.
} 
por dos altas columnas coronadas por sendas estatuas de leones, en apariencia de grandes dimensiones, animales que sin duda alguna hacen referencia al emblema de la ciudad y por extensión de la diócesis ubicada en ella.

La configuración del antiguo pretil la conocemos con bastante precisión gracias a dos grabados realizados por sendos artistas a finales del siglo XVIII, en ambos casos para ilustrar importantes publicaciones, con la intención de mostrar con la mayor fidelidad posible la catedral y darla a conocer al público en general. Por cierto, estos dibujos fueron realizados poco antes de que se decidiera la sustitución del viejo murete que hacía de frontera catedralicia, lo que aumenta su valor documental. Uno de ellos pertenece a la serie que hizo Fernando Sánchez Pertejo ${ }^{8}$, en la que se representan varias panorámicas de la catedral con el fin de incluirlas en la famosa obra del padre Risco sobre la iglesia legionense ${ }^{9}$; en la denominada Ortografía de la fachada principal de la Santa Iglesia de León se puede ver con bastante claridad la composición del cierre del atrio. Otro ejemplo es el grabado que acompaña al texto de Antonio Ponz en su Viaje de España, inserto en el capítulo dedicado a describir el primer templo de la capital leonesa ${ }^{10}$. Ambos dibujos son muy parecidos, de manera que las diferencias entre ambos no resultan sustanciales, algo lógico si pensamos que fueron hechos más con fin mimético que artístico (Lám. 4). Así, podemos deducir con bastantes garantías el as-

\footnotetext{
${ }^{8}$ Este arquitecto ya era entonces maestro de obras de la catedral de León, y posteriormente sería decisivo para la construcción del atrio, como veremos más adelante.

${ }^{9}$ Los dibujos fueron grabados por José Asensio y M. Navarro. Véase M. RISCO, Iglesia de León y monasterios antiguos y modernos de la misma Ciudad, Madrid, 1792.

${ }^{10}$ A. PONZ, Viage de España, t. XI, Madrid, 1787 (ed. facsímil 1972), p 200.
}

pecto que podía tener el cierre del atrio al llegar la última década del setecientos, muy poco tiempo antes de que fuera desmantelado para levantar el actual.

El cerramiento consistía en un sencillo muro de piedra de paredes lisas, que no parece que fuera de una altura superior al metro y medio, elevado sobre un zócalo. Estaba reforzado a tramos regulares por pilares de base cuadrangular, fuste liso y capiteles decorados. Encima de ellos se alzaba un león rampante portando un escudo, alternándose en el campo de cada uno de ellos leones y castillos, en alusión directa a las armas del reino de Castilla y León. Para acceder al atrio el muro disponía de una sencilla abertura, no muy amplia, enmarcada por sendos pilares como los descritos; estaba situada frente a la puerta central de la fachada occidental de la catedral y tenía unos escalones, lo que nos indica que el ándito estaba ligeramente elevado con respecto al nivel de la calle, lo mismo que en la actualidad.

En medio de esta estructura destacaba un artístico pilar de mayores dimensiones que los demás, realizado con una estudiada composición formal que le daba una apariencia más noble que la del resto del conjunto, por lo que presumimos que sería un monumento destacado; el padre Manuel Risco, cuando habla en su libro sobre el pretil del atrio, lo sitúa ... delante de Nuestra Señora la Blanca en la portada principal ${ }^{11}$.

$\mathrm{Su}$ esmerada factura y su privilegiada ubicación, le confería un indudable protagonismo, que sólo sería explicable si estuviera asociado con alguna función específica considerada de alto valor en su momento, ya que no parece que fuera un mero adorno intrascendente, ni por forma, ni por tamaño, ni por ubicación.

\footnotetext{
${ }^{11}$ M. RISCO, op. cit. , p. 58.
} 
Este singular elemento, a tenor de lo que podemos ver en los grabados citados, se elevaba sobre un zócalo que hacía de base para dos cuerpos de alzados rectangulares, superpuestos y rematados por un copete piramidal muy estilizado, adornado con ganchillos y coronado por un león que portaba una banderola (Lám. 5). El cuerpo inferior se engalanaba con adorno de arcos ciegos, mientras que el superior tenía una hornacina en cada frente, donde se colocaba una escultura humana ${ }^{12}$. En los documentos de la época consta que en el monumento estaba escrito un célebre dístico laudatorio que hacía referencia a la belleza del edificio de la catedral leonesa ${ }^{13}$. Antonio Ponz lo leyó en su momento e hizo la siguiente transcripción, que suponemos literal ${ }^{14}$ :

\section{-}

${ }^{12}$ El obispo FRANCISCO TRUJILLO escribió a finales del siglo XVI una Historia de la Iglesia de León, que fue transcrita en siglo XVIII por el canónigo archivero Carlos Espinos del Pi (17712-1777). Esta copia manuscrita de gran interés documental se conserva hoy en ACL, Códices, no 19. En el folio 191 v., hemos encontrado una descripción del monumento en los siguientes términos: ...delante de la portada de Nuestra Señora la Blanca, a donde esta un tropheo en esta manera: Un pilar alto, de piedra, ochavado, y en lo alto, junto al chapitel, en cada ochava una figura de Santo, y encima por remate una pirámide con un león sobre un moro caído con su alfanje, y en la mano tiene el león una bandera, que todo ello aunque no es de tanta antigüedad como el edificio de esta yglesia, prueba bien ser esta la tradicion de que el leon es la insignia de esta ciudad, y de los Reyes de Leon es señal de que ganaron por armas esta ciudad y su provincia de los moros y de que triunfaron de ellos.

${ }^{13}$ ACL, Actas Capitulares, caja 445, doc. 10.051, fol. $54 \mathrm{r}$. En junio de 1798, en plena polémica por la reforma del atrio, se hace mención del citado monumento del que se dice que es ...un pilar de bella arquitectura que estaba delante de la fachada principal y contenia una lapida con versos alusivos a la antiguedad y hermosura de la yglesia

${ }^{14}$ A. PONZ, op. cit., p 224, señala que la inscripción estaba escrita en "la torrecilla del atrio que mira a poniente". M. RISCO, op. cit., p. 58 dice: Léese también en el pilar que está delante de nuestra Señora la Blanca en la portada principal de la iglesia, un verso antiguo que engrandece el artificio de esta fábrica sobre todas las de Espa$\tilde{n} a$, y repite el dístico, aunque con algunas variantes en la trascripción, así, utiliza Hispaniis y egregiis. De forma
Sint licet Hispanis ditissima pulchraque Templa Hoc tamen egregius omnibus arte prius ${ }^{15}$.

La composición del monumento recuerda a los antiguos rollos de origen medieval que se utilizaban como símbolos de jurisdicción. Solían emplazarse en los cruces de caminos o en la entrada de las poblaciones, pero también en la plaza principal de muchas ciudades y pueblos españoles a finales de la Edad Media. Estos monumentos, de carácter judicial, no tenían una tipología estricta, más allá de la conformación más o menos artística de un pilar de piedra vertical con alguna forma de coronación especial y una base escalonada. A partir de este sencillo esquema las variaciones podían ser múltiples y depender tanto del modelo de financiación, como de la zona o la fecha en que fueron realizados ${ }^{16}$. Así

similar lo recogen P. MingOte y TARAZONA, Guía del viajero en León y su provincia, León, 1879, p.148, y J. M. QUADRADO, Recuerdos y bellezas de España. Asturias y León, Madrid, 1855, p. 306.

F. TRUjILLO, en su Historia de la Iglesia de León, en el folio 135 r., copia el letrero con ligeras variaciones, aunque se mantiene lo sustancial: Sint quamvis Hispanis ditissima pulchraque templa, hoc tamen egregiis omnibus arte prius.

${ }^{15}$ Se puede traducir por: Aunque los españoles tengan riquísimos y hermosísimos templos, sin embargo este es por su arte preferible a todos los más egregios.

${ }^{16}$ Sobre esta cuestión se puede consultar, C. BERNALDO DE QUIRÓS, La picota. Crímenes y castigos en el país castellano en los tiempos medios, Madrid, 1907; CONDE DE CEDILlo, Rollos y Picotas en la provincia de Toledo, Madrid, 1917; L. JIMÉNEZ ASUA, “Monumentos arquitectónicos penales", en Tratado de Derecho Penal, t. I, Madrid, 1949; J. M. FERRER GONZÁLEZ, "Rollos y picotas en la provincia de Guadalajara", Wad-Al-Hayara, no 7, Guadalajara, 1980, pp 103-140; A. GONZÁLEZ BLANCO, Horcas y picotas en La Rioja, Barcelona, 1984; I. CADIÑANOS BARDECI, "Rollos y cruceros en Burgos", en Revista de Dialectología y Tradiciones Populares, no 40, 1985, pp 69-114; L. MIRAVALLES RODRíGUEZ, Los rollos jurisdiccionales, Valladolid, 1996; F. M. OLIVIER LÓPEZ MERLO, Rollos y Picotas de Guadalajara, Guadalajara, 1998; S. TÁRREGA PÉREZ, Monumentos menores en la provincia de Burgos: inventario de picotas, rollos y cruceros, Burgos, 2000; J. M. GARCíA ROL, Los rollos jurisdiccionales en la comarca de Trujillo, Madrid, 2002. A. GONZÁLEZ BLANCO, "Horcas, rollos y picotas en la mentalidad del 
pues, no descartamos que en su origen fuera un rollo jurisdiccional de factura gótica, ubicado en la plaza principal y más emblemática de la ciudad, como durante mucho tiempo fue la de Santa María de Regla. Esta caracterización tiene trascendencia por lo que después diremos.

Son muy escasas las referencias explícitas referidas a esta peculiar pieza, de la que no tenemos ninguna noticia acerca de su posible autoría ni fecha de ejecución. La única reseña antigua que disponemos, la cual además resulta muy incompleta y sesgada, es la realizada en el año 1746 por Ascensio de Morales, miembro del Consejo de su Majestad y Oidor en la Audiencia de Sevilla. Por aquellas fechas vino a León para hacer un Reconocimiento y vista ocular de la iglesia Catedral de León, deteniéndose en recoger la presencia de múltiples escudos con las armas reales de Castilla y León que había por doquier en la catedral, con la finalidad de demostrar que el edificio era de fundación real. En su escrito, refiriéndose al cierre del atrio dice:

... y en el Atrio, que antecede a la expresada fachada se halla entre otras cosas exigida una Columna en forma piramidal, guarnecida de Estatuas, que sostiene a un Leon con una vandera en la mano, y por la parte que la dicha Columna mira a la referida Ygl(esi)a se registraron dos Tarjetas, la una con las Armas de Castilla y Leon ${ }^{17}$.

Los grabados que ilustran los libros de Ponz y Risco sólo representan la vista trasera del monumento, $\mathrm{y}$, aunque la descripción literaria de Ascensio de Morales hace mención también de la parte que da frente a la fachada del edificio catedralicio,

barroco", En torno al Barroco. Miradas múltiples, Murcia, 2006, pp 43- 55.

${ }^{17}$ Archivo Histórico Nacional, Leg. Estado. 3021, no 53. Catedral de León. Copias documentos. Privilegios 1751. El documento ha sido trascrito por A. FRANCO. "El estado de la catedral en 1751", El Filandón, Diario de León, 31-X-2004, pp. 2-3. no es lo suficientemente explícita como para que sepamos como era por ese lado.

La originalidad del citado elemento y la importancia que se dio a su desplazamiento durante el proceso de renovación del cierre del atrio, como veremos más adelante, nos indican que la pieza tenía un indudable valor emblemático y por esa razón algunos canónigos lucharon para que no se desmantelara y se mantuviera en un lugar privilegiado de la catedral. Estas circunstancias motivaron nuestra curiosidad y nos llevaron a detenernos en su estudio, poniéndolo en comparación con otro monumento singular que está en el pórtico de la catedral. Nos estamos refiriendo al famoso Locus Appellacionis, situado debajo del arco que separa la portada central de la conocida como de San Juan.

Al confrontar la configuración formal de ambos encontramos muchas similitudes. Así, si nos fijamos en la parte posterior del Locus Appellacionis y la vista que conocemos del otro monumento, vemos que el prisma que lo conforman tienen en ambos casos idéntico número de caras, aparece la misma disposición de delgadas columnillas en las aristas, con similares arcos lobulados en la parte superior, molduración semejante en la base, e incluso la proporción entre las distintas partes del conjunto parecen seguir una misma cadencia; en conclusión, todo es muy parecido para que sea evidente su relación $^{18}$.

\footnotetext{
${ }^{18}$ No obstante no son el mismo elemento, al contrario de lo que opina A. FRANCO, "El estado de la catedral..., cit., p. 2. El obispo F. TRUJILLO en su Historia de la Iglesia de León, escrita a finales del siglo XVI como ya dijimos, en el capitulo titulado De que el Locus Appellacionis que esta en la portada de Nuestra Señora la Blanca es manifiesta razon de la antiguedad de este edificio, describe a este monumento y lo emplaza ...situado entre la puerta principal de en medio y la colateral de la capilla de San Juan, por lo tanto en el mismo lugar que en la actualidad, por lo que no puede ser el mismo que en el
} 
La diferencia estaría en el cuerpo superior que tiene el monumento del pretil y que no está en el otro, así como en la columna incrustada que aparece en el Locus Appellacionis. Esta columna es el emblema de una de las instituciones más ancestrales de las que se tiene noticia en el antiguo reino de León ${ }^{19}$. Como indica la inscripción latina aludida, grabada en el fuste, marcaba el lugar concreto en el que se celebraban los juicios de apelación sobre los fallos de los tribunales reales ${ }^{20}$, allí donde los Jueces del "Libro" (Liber Iudiciorum) administraban justicia siguiendo la antigua jurisprudencia de la monarquía visigótica ${ }^{21}$. No es el momento ni el lugar apropiado para tratar sobre el significado jurídico y la trascendencia legendaria del monumento, entre otras razones porque ya ha sido estudiado con todo rigor por importantes especialis$\operatorname{tas}^{22}$, no obstante, si nos gustaría destacar

siglo XVIII todavía estaba en el cierre del atrio. Cfr., ACL, Códices, no 19, fol. 152 v.

${ }^{19}$ La columna es un elemento muy antiguo, probablemente romano, al que se le había concedido un carácter emblemático, siguiendo la tradición medieval de valorar aquellos objetos del pasado que han tenido en su historia alguna significación especial.

${ }^{20}$ Parece ser que antes de estar en el atrio de la catedral actual, el Locus Appelacionis pudo estar ubicado en la anterior sede catedralicia levantada en estilo románico, e incluso previamente en San Isidoro, así lo plantean por ejemplo A. FRANCO, "Escultura medieval", en La catedral de León, León, 2002, p. 115; A. G. CAVERO Domínguez, E. Fernández GonZÁlez, F. GALVÁN FREILE, "Images royales, images de la justice à la cathédrale de León", e-Spania. Revue électronique d'études hispaniques médiévales, no 2, 2006, http:/www.espania.paris-sorbonne.fr.

${ }^{21}$ J. PuYOL y AlONSO, Orígenes del Reino de León y sus instituciones políticas, León, 1926, p. 286.

${ }^{22}$ Remitimos a otros trabajos más específicos para conocer con más detalle todo lo perteneciente a este asunto. Véase, entre otros, C. SÁNCHEZ ALBORNOZ, "El "juicio del Libro" en León durante el siglo X", Anuario de Historia del Derecho Español, 1924, pp. 382-387; E. BENITO RUANO, "Locus Appelacionis", Estudios en homenaje a Don Claudio Sánchez Albornoz en sus 90 años, Instituto de Historia de España, Buenos Aires, 1985, pp. 303-313; A. FRANCO, Escultura gótica en León y provincia (1017-1230), León, 1998; L. MARTíNEZ ÁNGEL, que ambos monumentos estaban afrontados, limitando un espacio que estaba marcado por la simbología judicial. En esta zona de la fachada de la catedral están ubicadas las figuras de la Justicia Real, alegoría representada por una mujer tocada con corona que porta una espada en una mano y una balanza en la otra, al lado de las efigies de los reyes Salomón y David, relacionados de siempre con la justicia ${ }^{23}$. De esta manera quedaría limitado el marco espacial donde tenían lugar los actos jurídicos definidos por el Liber Iudiciorum ${ }^{24}$. Recordamos que la función judicial no ha sido extraña a los atrios de las catedrales desde la época medieval, siendo relativamente normal que delante de los pórticos de diversas catedrales, tanto españolas como europeas, se celebrara algún tipo de acto para administrar justicia en alguna de sus múltiples facetas, teniendo como marco representativo la fachada del templo ${ }^{25}$.

Cuando se iniciaron las obras para cercar el atrio con una nueva estructura, se produjo una polémica en el seno del cabildo sobre cuál debía ser el destino del monumental pilar, ya que el proyecto contemplaba simplemente la supresión del mismo, sin tener dispuesto un lugar alternativo para ubicarlo de nuevo. En estos momen-

“Locus Appelacionis de la catedral de León: Estado de la cuestión, propuesta de datación y otras consideraciones", León y su Historia. Miscelánea histórica, t. VIII, León, 2003, pp. 611-637; G. CAVERO DOMÍNGUEZ, E. FERNÁNDEZ GONZÁLEZ, F. GALVÁN FREILE, op. cit.

${ }^{23}$ Sobre estas esculturas, véase principalmente, A. FRANCO, Escultura gótica...

24 En G. CAVERO DOMínguez, E. Fernández GONZÁLEZ, F. GALVÁN FREILE, op. cit., se analiza con detalle el espacio, la iconografía y el significado de conjunto donde tenían lugar las apelaciones, que no variaría sustancialmente aunque "la columna" estuviera situada en cualquiera de las dos ubicaciones.

${ }^{25}$ Véase al respecto, entre otras referencias, A. FrANCO, Escultura gótica..., p. 210; B. DEIMLING, “La portada medieval y su importancia para la historia del derecho", El románico. Arquitectura, escultura, pintura, Colonia, 1996, pp 324-327. 
tos, finales del siglo XVIII, ya había perdido por completo su función primigenia, e incluso podemos deducir que se ignoraba el antiguo carácter que tuvo, pues los motivos esgrimidos para conservarlo se basaban más en su valor artístico o en servir de soporte para el dístico laudatorio, más que en su posible significado histórico, al cual no se alude en ningún momento.

Unos capitulares querían mantenerlo, por su belleza y antigüedad, mientras que otros querían quitarlo por no armonizar bien con la estética del nuevo atrio que se pretendía hacer ${ }^{26}$. En la reunión del cabildo celebrada en junio de 1798, el sr. Ruiz se opuso a la supresión por considerarlo de un extraordinario valor para la catedral por su bella factura. Sin embargo, tras la correspondiente deliberación, la mayoría de los capitulares consideraron que era mejor quitar el pilar porque era "disforme" a la nueva arquitectura del atrio, argumentando una cuestión estilística y de gusto para suprimir semejante vestigio de valor histórico y patrimonial ${ }^{27}$. A continuación, en el mismo capítulo, se pasó a deliberar si sería conveniente colocar en otra parte el pilar mencionado y, de ser así, dónde sería el mejor sitio para él; la conclusión fue que se desmontase con el mayor cuidado posible

${ }^{26}$ ACL, Actas Capitulares, caja 445, doc. 10.051, fol. $54 \mathrm{r}$.

(al margen) Propuesta sobre no derribar un pilar frente de la fachada principal de la yglesia y rebajo del atrio.

Hizo presente el señor Ruiz que en la obra del atrio de la yglesia se trataba de derribar un pilar de bella arquitectura que estaba delante de la fachada principal y contenia una lapida con versos alusivos a la antiguedad y hermosura de la yglesia y que protestaba asi contra el proiecto de que este monumento se quitase...

${ }^{27}$ ACL, Actas Capitulares, caja 445, doc. 10.051, fol. 54 r. Sólo apoyaron la propuesta de Ruiz unos pocos capitulares, según consta en el acta de la sesión: Protestaron esta resolucion y renovaron sus protestas anteriores contra toda la obra los señores Mayorga, Banamariel, Doctoral, Ruiz, Carpintero, Balbuena y Barra, cuias protestas fueron admitidas y se mando que aqui constasen. para no dañarlo y que se colocase en el centro del claustro

(Al margen) Mudese el pilar mencionado al medio del patio del claustro.

Se paso despues a deliberar entre los señores que no havian protestado si seria conveniente colocar en otra parte el pilar mencionado y a donde, y en vista de contener su lapida un monumento el mas autentico de la hermosura de esta yglesia por el juicio que de ella havian formado los mejores arquitectos de aquel tiempo, se acordo que se desiciese con el maior cuidado posible y colocase en el centro del patio del claustro haciendo memoria del dia y año y motibo de su translacion ${ }^{28}$.

Desconocemos si en aquel momento se cumplió el mandato, cosa que dudamos, pero no tenemos constancia documental de que en algún momento estuviera en el claustro según lo dispuesto. La falta de documentación nos impide saber las razones que motivaron la revocación de la primera decisión adoptada, ni dónde fue a parar. Dicha carencia documental también nos imposibilita establecer el desarrollo y la cronología de los hechos hasta llegar a su desaparición total. Por otro lado, nos llama la atención que la mayoría de los cronistas de los siglos XVIII y principios del XIX se ocuparon de los versos que elogiaban la belleza de la catedral y muy pocos se detuvieron en describir el soporte sobre la que estaba escrito, por lo que deducimos el escaso interés en el que había caído su antiguo significado.

\section{EL NUEVO ATRIO.}

Los datos conocidos nos indican que fue a lo largo del año 1793 cuando el cabildo de la catedral, con el consentimiento y el aval del obispo, que por aquellas fechas era Cayetano Antonio Cuadrillero Mota (17771800), decidió hacer una renovación completa del atrio; se empezó entonces y se

\footnotetext{
${ }^{28}$ ACL, Actas Capitulares, caja 445, doc. 10.051, fol. $54 \mathrm{r}$.
} 
alargó durante varios años ${ }^{29}$. Dentro de esta operación se contemplaba, como elemento decisivo de la obra, proceder a la sustitución del viejo pretil de piedra heredado por otro moderno que estuviera más acorde con los gustos imperantes en aquella época de fin de siglo. El nuevo cierre se levantó sobre los cimientos del pretil antiguo, como pudo comprobar Demetrio de los Ríos cuando preparaba los cimientos para el andamiaje y apuntalamiento del hastial occidental con motivo de las labores de restauración de la catedral leonesa ${ }^{30}$.

El plan de trabajo aprobado contemplaba también el enlosado y la rebaja de la cota del suelo del atrio. Ambas cosas se hicieron, aunque algunos canónigos no estuvieran de acuerdo con ésta porque consideraban que a la larga sería perjudicial para la solidez del edificio ${ }^{31}$. A esta obra se deberá probablemente el zócalo de piedra veteada rosa que tiene la catedral en la parte baja de los muros situados a lo largo de la zona del atrio, muy distinta a la caliza del resto de la fábrica e idéntica a la utilizada para las losas del atrio.

El arquitecto encargado de realizar el proyecto definitivo, así como de llevarlo a la práctica hasta su conclusión, fue Fernando Sánchez Pertejo, una personalidad destacada en el panorama constructivo leonés de finales del siglo XVIII y primera mitad del XIX ${ }^{32}$; padre de Perfecto Sánchez Ibáñez

\footnotetext{
${ }^{29}$ La construcción del cierre del atrio ha sido tratada en sus aspectos más generales por J. E. GARCíA MELERO, catedrales góticas en la España de la Ilustración, p. 30-33; J. Rivera BlaNCO, Historia de las restauraciones..., pp. 151-157.

${ }^{30}$ D. DE LOS RíOs, ob. cit, t. II, p. 36.

${ }^{31}$ ACL, Actas Capitulares, caja 445, doc. no ${ }^{\circ} 10.051$, fol. $54 \mathrm{r}$.

${ }^{32}$ Algunas de sus realizaciones se tratan en E. Morais VALLejO, "El Castillo de León. Breve historia de un valor patrimonial", De Arte, no 4, León, 2005, pp. 135-160; véase también, V. FERNÁNDEZ VÁZQUEZ, Diego de Ochoa. Arquitecto y académico de mérito de San
}

y abuelo de Isidoro Sánchez Puelles, que también fueron, como él, arquitectos oficiales de la Catedral y del Ayuntamiento. Su prestigio en León se empezó a fundar en 1787 , a los veinte años de edad, cuando consiguió el primer premio de segunda clase de arquitectura de la Real Academia de Bellas Artes de San Fernando ${ }^{33}$, con medalla de oro de una onza entregada en acto solemne por el Conde de Floridablanca ${ }^{34}$, la misma institución que le concedió en el año 1794 el título de arquitecto $^{35}$. Aunque en algún momento trabajó a las órdenes del célebre Ventura Rodríguez ${ }^{36}$, la mayor parte de su actividad arquitectónica la desarrolló en León, donde estuvo afincado hasta su muerte y construyó edificios de todo tipo. En esta ciudad consiguió primero el cargo de maestro de obras de la cate$\mathrm{dral}^{37}$, y posteriormente el de arquitecto municipal $^{38}$.

Fernando, León, 2000, pp. 78-80; M. CAYÓN WALDALISO, "Sánchez Pertejo", Diario de León, 10-II-1987, p. 36.

${ }^{33}$ Sobre el tema de los premios de la Real Academia, véase, A. QUINTANA MARTíNEZ, La Arquitectura y los arquitectos en la Real Academia de Bellas Artes de San Fernando, Madrid, 1983, pp. 85-90 y 125-130.

${ }^{34}$ Archivo de la Real Academia de San Fernando (desde aquí, AASF), libro 3/85, fol. $52 \mathrm{r}$.

${ }^{35}$ AASF, libro 3/85, fol. 283 r: ...la Junta enterada del acuerdo de la referida extraordinaria, y de los meritos y estudios de estos discípulos, tuvo a bien de resolver que a Pertejo se le despachase el titulo de Arquitecto.

${ }^{36}$ AASF, libro 3/85, fol. 184 r: Don Fernando Sánchez Pertejo ... exponía sus estudios y premios en esta Academia, su práctica y exercicio bajo sus maestros el difunto Bentura Rodríguez y su sobrino Dn. Manuel Martín.

${ }^{37}$ ACL, Actas Capitulares, caja 444, doc. no 10.048 , fols. 165 v y $166 \mathrm{r}$ : ... la diputacion haviendo reconocido los documentos que presenta don Fernando Sanchez Pertejo en prueba de hallarse examinado arquitecto por la Academia de Nobles Artes de San Fernando y el certificado dado por el secretario de la misma, no halla reparo en que se le pase a nombrar arquitecto de la fabrica con arreglo a la citada orden.

${ }^{38}$ El 4 de enero de 1795 la Junta ordinaria de la Real Academia de Bellas Artes recibió la noticia, según consta en las actas. AASF, libro 3/86, fol. 3: ...Leí una carta que desde León habia escrito Dn. Fernando Sanchez Pertejo, poniendo en noticia de la Academia que aquella 
La construcción del nuevo atrio estuvo acompañada desde el principio de toda índole de controversias, lo cual sería uno de los principales motivos por los que la terminación de la obra se dilatara durante mucho más tiempo de lo previsto inicialmente $^{39}$. La primera polémica fue de base, ya que se cuestionó si era realmente necesario hacer un nuevo cierre del atrio o bastaba con arreglar el antiguo. A partir de ahí se cuestionó desde la contratación del herrero para hacer las rejas, hasta el precio que se debía pagar por el hierro que se necesitaba para ellas. En cuanto a cuestiones artísticas, se planteó el estilo que se debía utilizar, ya que mientras unos defendían que se hiciese según las nuevas formas, otros creían que debía seguirse la línea antigua para armonizar mejor con el gótico catedralicio. En medio de esta discusión surgió otro problema, en el que tuvo que intervenir la Real Academia de Bellas Artes de San Fernando para aprobar la obra y dar su consentimiento a las trazas proyectadas. Por último, recordamos las discusiones que se plantearon sobre la oportunidad de quitar el antiguo monumento que adornaba el pretil y servía de halago del edificio, que vimos más arriba. Todas estas polémicas se vivieron en el seno del cabildo de la catedral de manera muy viva, hasta el punto de que se dividió en dos bandos claramente diferenciados, que se emplearon a fondo para hacer prevalecer sus tesis sobre las del contrario, teniendo al obispo como poder moderador. Aunque las discusiones tuvieran a veces argumentos estilísticos, otras veces religiosos o incluso algunos de índole económica, no podemos descartar que muchas veces los enfrentamientos eran en realidad perso-

Ciudad acababa de concederle, con aprobación del Consejo, la plaza de Arquitecto de ella con la dotación de quatrocientos ducados. La Junta estimó la atención de Pertejo, y me mandó que así se lo manifestase.

39 Algunas de estas polémicas se tratan en J. EgUiAgARAY PALlarés, La azarosa vida del clérigo don Rafael Daniel Sánchez, León, 1964, pp. 37-42. nales y atendían a rencillas particulares ${ }^{40}$. A continuación pasamos a tratar estas cuestiones, al tiempo que veremos como se iba construyendo el nuevo atrio hasta su conclusión.

Desde el principio hubo una minoría de capitulares, encabezados por los señores Benamariel y Herrera Lorenzana, que estuvieron en contra de la realización del nuevo atrio, e incluso llegaron a tratar de involucrar a la Academia de Bellas Artes para ganarla a su causa. Con el fin de defender su postura esgrimían diferentes razones, que encontramos resumidas en la reunión del cabildo del 9 de enero de 1794 cuando se propuso aprobar la obra. La primera de ellas era que el cabildo no tenía conocimiento del proyecto, por lo que carecía de información sobre las condiciones de los trabajos, el coste real que iban a tener, ni cuál sería la financiación, por lo que estaban convencidos de que esta institución no estaba en condiciones de resolver el remate de la obra ni de dar el visto bueno a un contrato del que desconocía lo fundamen$\mathrm{tal}^{41}$. En segundo lugar, los opositores al proyecto invocaban la necesaria autorización de la Real Academia de San Fernando para realizar cualquier obra de importancia en la catedral, conforme estaba convenido en la reglamentación de la época sobre los monumentos religiosos; la verdad es que no se tenía tal autorización porque ni tan siquiera se había solicitado. Había varios Decretos firmados por Carlos III, todavía en vigor, por los que se encomendaba a la Academia el control de las obras públicas que se hicieran en el reino de España. Uno de ellos, firmado el 23 de octubre de 1777, obligaba a pasar la censura previa de la Academia a todas las obras públicas que se

\footnotetext{
${ }^{40}$ Así lo pone de manifiesto para casos similares de otras catedrales J. E. GARCíA MELERO, Las catedrales góticas ..., p. 114.

${ }^{41}$ ACL, Actas Capitulares, caja 444, doc. no 10.048 , fols. 136.
} 
hiciesen en adelante en España. En otro, aprobado el 24 de noviembre del mismo año que iba dirigido particularmente a todos los obispos, se exigía un control de las obras en edificios religiosos para evitar que se construyese en ellos contra las reglas del arte. Esta normativa sería reiterada posteriormente con otras reales órdenes de 1789 y $1798^{42}$. Con este control de las obras la Academia pretendía sustituir las voluptuosas formas del barroco castizo por la morfología neoclásica, uniformando estilísticamente la arquitectura española y dando validez universal a los cánones académi$\cos ^{43}$.

Los decretos citados fijaban que las autoridades eclesiásticas estaban obligadas a entregar previamente a la Academia los diseños de las plantas, alzados y cortes de las futuras fábricas, con el fin de proceder a su examen y dictaminar sobre la calidad del proyecto o los errores que pudieran tener. Así, expresamente se advierte a los obispos que están obligados siempre a consultar a la Academia

...para que en adelante cuiden de no permitir se haga en los templos de su distrito y jurisdicción obra alguna de consecuencia, sin tener dada seguridad del acierto, ...siempre que éstos, ya sea a propias expensas, o ya empleando caudales con que la piedad de los fieles contribuya, dispongan hacer obras de alguna entidad ${ }^{44}$

${ }^{42}$ A. MUÑOz COSME, La conservación del patrimonio arquitectónico español, Madrid, 1989, p. 22.

${ }^{43}$ M. M. V. SANZ SANZ, "Docencia y titulación en las Reales Academias. Control académico en la construcción", Anales de Historia del Arte, 1990, no 2, pp. 170171.

${ }^{44}$ R. O. de 23-X-1777, Ley III, Título XXXIV, Libro VI, Execución de obras públicas con precedente consulta de sus dibujos a la Academia de San Fernando; 24-XI-1777, Ley V, Título II, Libro I, Modo de executar las obras ocurrentes en todas las iglesias y sus altares. Ambas leyes recogidas en Legislación sobre el Tesoro Artístico de España, Madrid, 1957, pp 39-41.

Sobre este tema véase, C.BÉDAT, La Real Academia de Bellas Artes de San Fernando (1744-1808), Madrid,
Actuando de esta manera, los canónigos discrepantes se alzaban en paladines de la legalidad que defiende los monumentos artísticos y defensores del buen gusto, frente a las posibles arbitrariedades de las innovadoras ideas estilísticas no contrastadas académicamente. Joaquín Herrera Lorenzana recuerda al respecto lo sucedido con el retablo de la capilla mayor de la propia catedral leonesa, realizado por Narciso Tomé con satisfacción del cabildo, que, sin embargo, pronto recibió las más duras y aceradas críticas de los eruditos ilustrados defensores de la ortodoxia, siendo reprobado por ellos al considerarlo contrario al arte $^{45}$. Así, trae a colación la opinión de Antonio Ponz, para que no se repita con el atrio lo que sucedió en su día con el retablo

...su cumplimiento es mui conveniente al
buen aspecto de la magnifica fabrica de nues-
tra yglesia que no deve exponerse a ridiculos
adornos como ha parecido al Sr. Ponz el re-
tablo de la capilla maior, que se hizo segun se
dice por tradicion constante, a causa de un
voto de exceso en el acuerdo, que contradije-
ron muchos, como sucede en el dia con la ci-
tada obra del atrio que se reclama por algu-

1989, pp 381-382; S. ARBAIZA BLANCO, “La Academia y la conservación del patrimonio", Academia, 1999, no 89, p. 30.

${ }^{45}$ Recordamos que el espléndido retablo de Tomé lo desmontó Demetrio de los Ríos y después de troceado, se trasladó en parte a la iglesia de los franciscanos de la misma ciudad de León. Véase sobre este tema, entre otros, F. ÁLVAREZ, "La pulchra leonina y su retablo de la capilla mayor", Archivos leoneses, no 12, León, 1952, pp. 95-109; J. A. MOREIRO GONZÁLEZ, “El retablo de Thome en la iglesia de S. Francisco, en León", Tierras de León, no 49, León, 1982; J. M. PRADOS GARCÍA, "El retablo mayor del siglo XVIII de la catedral de León", Archivo Español de Arte, t. 55, no 220, pp. 329-350; J. RIVERA BLANCO, "Narciso Tomé y los restos del Colegio Apostólico del antiguo retablo de la catedral de León", B.S.A.A., no 43, Valladolid, 1977; F. LLAMAZARES RODRÍGUEZ, El retablo barroco en la provincia de León, León, 1991, pp. 362-374; E. MORAIS VALLEJO, "La transformación barroca del interior de la catedral de León. Una idea con una larga gestación", De Arte, no 5, León, 2006, pp. 133-155. 
nos juzgandola intempestiva y de ninguna manera necesaria ${ }^{46}$.

Otro argumento que esgrimían los capitulares disidentes era la poca oportunidad de las obras, pues los tiempos de crisis económica que corrían, las calamidades sociales que se estaban produciendo y la incertidumbre del futuro más inmediato, no parecían ser los más propicios para gastar dinero en obras que no estaban consideradas como necesarias ni urgentes. Por todas estas razones solicitaban la suspensión de las obras, cosa que no consiguieron porque la mayoría del cabildo era partidaria de la ejecución del nuevo atrio. Tampoco lograron que se informase de sus protestas al prelado de la diócesis, porque la asamblea estimó que no procedía hacerlo por no ser una práctica habitual, con lo cual la polémica no llegó por el momento a conocimiento de la máxima autoridad diocesana ${ }^{47}$.

No obstante, el capitular Joaquín Herrera y Lorenzana, que se había convertido ya en el cabecilla de los contrarios al proyecto, insistió a los pocos días sobre los mismos argumentos. Volvió a reiterar que la obra no era necesaria, que se podría suplir por un arreglo del antiguo pretil, viejo y deteriorado aunque recuperable, y que era mejor destinar el resto del dinero a otras cuestiones más urgentes o primordiales para iglesia. Entre ellas destacaba el ejercicio de la caridad para socorrer a los muchos indigentes que había en la diócesis, o hacer otras obras que eran mucho más necesarias, como reparar ciertas partes del edificio catedralicio que estaban más deterioradas, o a hacer una nueva sacristía para sustituir la antigua, muy dañada por el paso del

${ }^{46}$ ACL, Actas Capitulares, caja 444, doc. n⿳⺈ 10.048, fols. $138 \mathrm{v}$ y $139 \mathrm{r}$.

${ }^{47}$ ACL, Actas Capitulares, caja 444, doc. $n^{\mathrm{o}} 10.048$, fols. 135-136. En el acta se citan a los señores Benamariel, Maestrescuela, Bayón, Galiano, Herrera, Balbuena, Galindo y Barra como los únicos opositores al proyecto. tiempo. Esto, y otras muchas cosas más, antes que gastar los caudales de la catedral en algo prescindible, decía el canónigo, sobre todo teniendo en cuenta que las arcas estaban vacías, hasta el punto de mantener unos salarios muy bajos para los dependientes de la catedral, o tener que suprimir algunos oficios religiosos con el fin de ahorrar dinero ${ }^{48}$. Le parecía increíble a Joaquín Herrera que el cabildo no fuera consciente de la situación y que no se percatara de las consecuencias futuras que tendría la falta de previsión de su fallo

... bien consideradas causara admiración que un cavildo que se compone de hombres tan doctos y prudentes otorgue escritura para en el día hacer una obra nada precisa y tan costosa de la que solo resultara interes a cuatro o seis que no son del pais y ninguno a tantos pobres jornaleros de esta ciudad y sus cercanias que en estos tiempos calamitosos andan pordioseando de puerta en puerta por no tener en que emplearse, cuanto mejor seria que parte del dinero que havria de costar la obra, supuesto que en nombre de la fábrica nada se ha ofrecido en las presentes circunstancias a $S$. $M$, se destinase para socorro de tantas mugeres, viudas y pupilos de aquellos naturales de este Obispado que han sacrificado y sacrifican sus vidas por Dios, por el Rey y por la Religión, ${ }^{49}$.

Asimismo, el capitular recordaba de nuevo que existía una orden real que obligaba a tener un informe previo de la Academia con la aprobación para iniciar los trabajos, del cual se carecía y por lo tanto la obra no era legal ${ }^{50}$. A pesar de que la argumentación de los críticos estaba apoyada en sólidas evidencias, la propuesta, al ser apo-

\footnotetext{
${ }^{48}$ El capitular Herrera pone el ejemplo de la misa de doce que se suprimió para no pagar a un sacerdote: ... en tanto grado que por no gravarla con el aumento de un real o dos mas del estipendio al sacerdote que celebraba la misa de doce se quito esta, privando de este beneficio al pueblo, ACL, Actas Capitulares, caja 444, doc. $\mathrm{n}^{\mathbf{0}}$ 10.048, fol. $139 \mathrm{v}$.

${ }^{49}$ ACL, Actas Capitulares, caja 444, doc. no 10.048 , fol. $140 \mathrm{v}$

${ }^{50}$ ACL, Actas Capitulares, caja 444, doc. nº 10.048, fols. $137 \mathrm{v}-139$.
} 
yada por una minoría de los canónigos, fue rechazada nuevamente. El cabildo decidió seguir adelante con su idea inicial

Llamose despues al notario Dn Diego Ybañez y haviendo entrado en la sala capitular se otorgo ante el formalmente y con todas las clausulas de derecho el poder a los señores Zea y Pizarro para tratar de concluir y rematar el ajuste de la obra bajo el plan, traza y condiciones que mejor les pareciese con atencion a la dignidad de la obra y maior utilidad de la fabrica, y escriturar a nombre del cavildo la contrata ${ }^{51}$.

Joaquín Herrera, a pesar de las sucesivas negativas, no desistió y, derrotado en primera instancia, llevó su protesta ante la misma Academia de Bellas Artes. Hizo un informe, al que acompañaban la protesta que hizo ante el cabildo y una representación dirigida al Rey, comunicando que el cabildo de la catedral leonesa pensaba hacer una obra en el edificio histórico sin contar con el preceptivo informe de la institución que tenía la prerrogativa de aprobar$10^{52}$. La Academia, ante esta situación, decidió escribir al obispo para mediar en el conflicto entre las partes litigantes. No obstante, recuerda que ella no puede intervenir en la decisión de hacer o no un atrio nuevo, ni arbitrar en las desavenencias existentes entre Herrera, el obispo y el cabildo, pues su misión es primordialmente velar y cuidar de que no se hagan obras inperfectas y ruinosas que desacrediten la Nacion o amenazen las vidas de las personas que habiten los edificios, o hagan gastar inutilmente a los dueños sus caudales ${ }^{53}$. La respuesta trataba de presentarse como una postura conciliadora entre las partes, sin dar la razón plenamente a ninguna de las $\operatorname{dos}^{54}$, aunque sí reconoce que al Sr. Lo-

\footnotetext{
${ }^{51}$ ACL, Actas Capitulares, caja 444, doc. no 10.048 , fol. $141 \mathrm{r}$.

${ }^{52}$ J. E. GARCíA MELERO, Las catedrales góticas..., p. 114.

${ }^{53}$ AASF, libro, 32-5/2, s/f.

${ }^{54}$ J. E. GARCía MELERO, Las catedrales góticas ..., p. 117.
}

renzana le asiste todo el derecho cuando pide que no se ejecute bajo ningún concepto la obra sin que los planos o trazas fueran previamente vistos y aprobados por la Real Academia de San Fernando, como estaba recogido de manera clara en la Real Orden de S. M. de 23 de julio de 1789. Así pues, los términos son claros y concluyentes en cuanto a las obligaciones previstas antes de proseguir la obra ${ }^{55}$. La Academia ya contaba en el reinado de Carlos IV (1788-1808) con la Comisión de Arquitectura, fundada en 1786, que tenía como principal objetivo supervisar los proyectos arquitectónicos de envergadura que se hicieran en toda España, de manera que la mayor parte de las intervenciones realizadas en las catedrales españolas se hallaban bajo el estricto control burocrático de dicha Comisión, que actuaba para controlar la calidad y la adecuación de las nuevas obras con el edificio histórico ${ }^{56}$.

Los trabajos ya habían comenzado bajo la dirección de un maestro desconocido para nosotros, pues en el escrito que remite la Real Academia se dice que lo hecho hasta el momento, contraviniendo notoriamente la Real Orden de S. M. de 23 de julio de 1789, es todavía poco, reduciéndose al apoyo y postes que han de recibir las verjas de hierro ${ }^{57}$. Por todo lo expuesto, la Academia insta para que se actúe conforme a la normativa y cuanto antes remitan el proyecto para su aprobación ${ }^{58}$. Se aprovecha la ocasión para recordar que las más altas instituciones y los edificios más ilustres, como es el caso de la catedral de León en ambas facetas, deben ser los prime-

\footnotetext{
${ }^{55}$ AASF, libro, 32-5/2, s/f.

${ }^{56}$ J. E. GARCíA MELERO, Las catedrales góticas..., p. 30-33

${ }^{57}$ AASF, libro, 32-5/2, s/f.

58 J. E. GARCÍA MELERO, “Espiritualidad y estética: las transformaciones en los exteriores de las catedrales góticas españolas en el siglo XVIII", Hispania Sacra, 1989, no 41, p. 630 .
} 
ros en dar ejemplo con el cumplimiento de las leyes y en la elección de maestros competentes y reconocidos

...Y como el buen exemplo lo deben dar los cuerpos mas ilustres, y la catedral misma de Leon es uno de los edificios mas singulares que en su linea se admiran en España, hay doble razon para que aquel $R$. Obispo y $C a-$ bildo cumplan exactamente las Reales Ordenes de S. M. y para que no se emprendan alli obras por maestros ignorantes, de quienes no se tiene noticia ${ }^{59}$.

La nueva normativa generó en muchas ocasiones tensiones entre los cabildos de las catedrales y la Academia ${ }^{60}$, porque aquellos consideraban sus edificios como patrimonio particular sobre el que podían actuar a su antojo, mientras que ésta exigía el cumplimiento de la legalidad y quería imponer sus criterios artísticos y ejercer un férrea autoridad para evitar que la actividad arquitectónica derivase por derroteros heterodoxos sin control.

La circunstancia generada fue explotada hábilmente por Fernando Sánchez Pertejo, quien, a la vista del cariz que tomaban los acontecimientos, decidió sacar el máximo provecho personal de la situación. Así, en razón de los trabajos que estaba realizando para la catedral leonesa, en abril de 1794 pidió ser nombrado oficialmente como maestro de obras de la fábrica ${ }^{61}$, sustituyendo en el cargo al arquitecto Fernando de Compostizo, su antecesor ya fallecido ${ }^{62}$. El cabildo, sin mucha discusión, aceptó la propuesta para cumplir una de las premisas exigidas por la Academia y lo contrató de inmediato con un salario anual de $400 \mathrm{du}$ cados, cantidad que consideramos muy

${ }^{59}$ AASF, libro, 32-5/2, s/f

${ }^{60}$ J. E. GARCÍA MELERO, “Espiritualidad y estética ..., p. 608

${ }^{61}$ ACL, Actas Capitulares, caja 444, doc. 10.048, fol. $163 \mathrm{v}$.

${ }^{62}$ Sobre este arquitecto véase E. MORAIS VALLEJO, Aportación al barroco en la provincia de León. Arquitectura religiosa, León, 2000, pp. 62, 315-316. estimable y generosa ya que superaba en cien ducados a los que cobraba su predecesor en el cargo:

...haviendo reconocido los documentos que presenta don Fernando Sanchez Pertejo en prueba de hallarse examinado arquitecto por la Academia de Nobles Artes de san Fernando y el certificado dado por el secretario de la misma, no halla reparo en que se le pase a nombrar arquitecto de la fabrica con arreglo a la citada orden, antes lo tiene por mui preciso y necesario... y por lo que respecta al salario ... cree que debe darsele a Sanchez quatrocientos ducados anuales con la precisa obligacion de tener su domicilio en esta ciudad, de lebantar todos los planes y trazas de las obras que se construien en la fabrica de esta santa yglesia sin estipendio alguno y tambien de las obras de yglesias donde la fabrica tenga intereses... ${ }^{63}$.

Como vemos, uno de los argumentos esgrimidos para nombrar a Sánchez Pertejo fue el hecho de que fuera un arquitecto aprobado por la Real Academia de Bellas Artes de San Fernando, aunque no tuviera el título de Académico de Mérito ${ }^{64}$, como determinaba expresamente la Circular publicada el 28 de febrero de $1787^{65}$. Pero la razón no estribaría sólo en la garantía de

${ }^{63}$ ACL, Actas Capitulares, caja 444, doc. 10.048, fols. $165 \mathrm{v}$ y $166 \mathrm{r}$.

${ }^{64}$ Sánchez Pertejo no llegó a aprobar el examen de académico de mérito, según se recoge en la Junta de 2 de marzo de 1794, AASF, libro 3/85, fol. 283r., ...fueron de unánime parecer los señores examinadores que no hallando en él la extensión de conocimientos y ciencias necesarios en el arte para el grado superior que tiene que dar la Academia y es el de académico de mérito, sólo le hallaban suficiente para graduarle de Arquitecto.

${ }^{65}$ La disposición legislativa citada disponía que los arquitectos o maestros mayores de las capitales y cabildos eclesiásticos fueran académicos de mérito de la de San Fernando o la de San Carlos. Cfr. J. E. GARCíA MELERO, Las catedrales góticas..., p. 30.

El título de académico de mérito estaba contemplado en los estatutos de 1757. Era considerado como un grado para ser profesor de la Academia, o bien como un honor a añadir al currículo profesional de cada artista o arquitecto. Cfr. M. P. GARCíA SEPÚLVEDA y E. NAVARRETE MARTíNEZ, Relación de miembros pertenecientes a la Real Academia de Bellas Artes de San Fernando, Madrid, 2005, p. 6. 
tener un profesional acreditado por un título de carácter oficial, sino también en la posibilidad de disponer de un interlocutor cualificado para conseguir más fácilmente la aprobación de la institución académica de las obras que se iban a abordar en la catedral a partir de entonces.

A pesar de la nueva situación, Joaquín Herrera no renunció en su lucha contra el nuevo atrio, llegando hasta las más altas esferas del poder. Llevó sus quejas hasta el monarca, y supo, por medio de un agente de la Secretaria de Estado, que el rey había ordenado al prelado leonés que mandase los planos para su aprobación antes de proseguir con la obra, a lo cual se había comprometido el obispo ${ }^{66}$.

Por fin, las presiones hicieron efecto y la Real Academia recibió dos proyectos distintos para su estudio y autorización. Uno era el realizado por el recién nombrado maestro de obras de la catedral y otro el de un arquitecto desconocido, del que no se cita en la documentación ni tan siquiera el nombre:

Presentaronse en primer lugar a la censura dos diseños, executados el primero por el arquitecto dn. Fernando Sánchez Pertejo con destino a la construcción de unos pedestales con sus remates y emberjado con que se proyecta cerrar el atrio de la Santa Iglesia Catedral de León, y el segundo copia de otro de mano desconocida para el mismo intento bajo cuya idea se había tratado anteriormente de formar el dicho cerramiento ${ }^{67}$.

${ }^{66}$ ACL, Actas Capitulares, caja 444, doc. $n^{\mathrm{o}}$ 10.048, fols. 173 v. y 174.

${ }^{67}$ Este arquitecto probablemente sería el que había iniciado las obras, pues 16 años después de proyectado el nuevo atrio, cuando el cabildo determinó suspender de empleo y sueldo a Sánchez Pertejo por problemas económicos de la fábrica, este, en sus alegaciones, recuerda que en su momento fue él quien hizo ...el plano y dibuxo del atrio que a la sazon se estaba haciendo, y en seguida se puso a su execucion con el ahorro de mas de 200 (d) mil rs. del que tenian comenzado, sin la fealdad e
Por su parte, Fernández Pertejo, a los pocos días de ser nombrado maestro de obras de la fábrica catedralicia, escribió una carta al Secretario de la Academia, en aquellos momentos Isidoro Bosarte ${ }^{68}$, en la que pedía que fuera examinado su proyecto por los académicos ${ }^{69}$. Acompañaba la misiva con los dibujos de la planta y los alzados del cierre del atrio, diseñados con dignidad $\mathrm{y}$ arte, pero sin excesivo coste y procurando no dificultar la circulación de las calles circundantes, según su declaración de intenciones $^{70}$ (Lám. 6).

A la vista de las trazas ${ }^{71}$, la Junta Ordinaria de la Academia celebrada el 31 de mayo de 1794, decidió aprobar uno de los dibujos que había presentado Fernando Sánchez Pertejo, aunque con algunas modificaciones, que por su alcance transcribimos:

... Aprobó la Junta el trozo de obra que tuvo por mas arreglado entre los varios que venían demostrados por Pertejo, que se anotó

irregularidad que a Vuestra Santa Iglesia consta, cfr. ACL, doc. $8.961, \mathrm{~s} / \mathrm{f}$.

${ }^{68}$ Isidoro BOSARTE (1747-1807), fue secretario de la Real Academia de San Fernando desde 1792. Su teoría se encuentra repartida entre sus escritos, entre los que destacan para el tema que nos ocupa, Discurso sobre la restauración de las Bellas Artes en España. Disertación sobre el estilo que llaman gótico en las obras de arquitectura. Madrid, 1798; Viaje artístico a varios pueblos de España, con el juicio de las obras de las Tres Nobles Artes, que en ellos existen, y épocas a que pertenecen. Madrid, 1804. Sobre este personaje de gran trascendencia para la actividad de la Academia, véase, J. E. GARCÍA MELERO, "Cartas a Bosarte desde Roma", en Academia, Madrid, 1990, no 70, pp. 337-382; J. E. GARCíA MELERO, Las catedrales góticas..., p. 33-44.

${ }^{69}$ AASF, 32-5/2, s/f.

${ }^{70}$ Mui Sr mio: Remito a V. S. el dibuxo que manifiesta la Ydea en planta y alzado de los pedestales, remates y emberjado con que se intenta cerrar el Atrio de esta Santa Yglesia Cathedral, y he formado por orden de los comisionados del Ylmo Cabildo sugetandome en el todo a los medios del perimetro de las fachadas y delicadeza de la Yglesia procurando al mismo tiempo no sea de mucho coste, y no impida el desaogo de las calles. AASF., 32-5/2, s/f.

${ }^{71}$ Las trazas se conservan en ACL, Fondo Restauración. Inventario de Planos, no 462 . 
con la letra $A$ y sobre el qual se hicieron las prevenciones siguientes: que la barra orizontal del emberjado delineada sobre el collarino del pedestal atase precisamente con este miembro, quedando la otra que le sirve de paralela sujeta al plafon de la cornisa del propio pedestal, cuya corta reforma no impedia que en el intervalo de ambos yerros se acomodase el mismo adorno de postas, continuadas indicado en el sobredicho trozo aprobado. Que se llevase a efecto la puerta dispuesta por el citado Pertejo, recomendando toda la seguridad y solidez propia de su buen uso, executandose lisos los quatro paramentos de los pedestales de la obra y siguiendo uniformemente en toda ella la idea preferida ${ }^{72}$.

Comprobamos que las indicaciones ofrecidas por la Comisión académica son muy simples, dedicándose más a cuestiones técnicas para garantizar la seguridad y solidez de la verja que a razones estilísticas. Tan sólo hay recomendaciones estéticas en el adorno de las postas y en sugerir la desnudez de los pedestales para asegurar la pureza de las formas y los valores clasicistas; todo parece indicar que Fernández Pretejo hizo un proyecto sencillo, sin grandes invenciones, acorde con el gusto académico (Lám. 7). Después de la encendida polémica suscitada, de las advertencias dadas por el cabildo sobre la inadecuación de mezclar estilos distintos en un edificio histórico de la categoría de la catedral leonesa, y de la importancia que tenía para la Academia de Bellas Artes el control de los monumentos españoles, nos parece que el informe resulta pobre e incluso decepcionante. En resumen, podemos decir que el dictamen atiende sólo a cuestiones menores y no aprovecha la ocasión para crear una verdadera ciencia restauradora, para ofrecer criterios útiles en las intervenciones sobre edificios históricos y dictar doctrina sobre la manera de intervenir en monumentos antiguos que son patrimonio artístico e histórico. Es evidente que la Academia

\footnotetext{
${ }^{72}$ AASF, libro 3/139, fol. 248v y 249r.
}

todavía no tenía una política clara sobre la manera de actuar en los exteriores de las catedrales góticas, limitándose a dar indicaciones muy concretas para un caso particular, no a proclamar valores de orden general en aras de fijar teoría. Al analizar las actuaciones en diversos lugares y fechas, se pone de manifiesto que no hay una forma unitaria de enfrentarse al gótico, sino que todo queda sumido en las intenciones generales de la institución, como pueden ser el control de los diseños, el empleo de materiales nobles, la sencillez de las formas, y el desprecio de todo lo que pueda parecer barroco $^{73}$.

Una vez obtenido el pertinente permiso académico para proseguir las obras, éstas continuaron, aunque a un ritmo no demasiado rápido y tampoco exento de nuevas controversias y problemas, como la ya tratada al comentar el destino del pilar adosado al pretil. Uno de los primeros asuntos de la discordia, que podríamos catalogarlo como de orden doméstico, aunque no por eso de menos trascendencia, fue el relativo al hierro necesario para la realización de la verja.

En enero de 1794 la obra ya estaba en marcha y surge la primera polémica. En la reunión del cabildo del día 7 se leyó el memorial presentado por Carlos Buxtorg ${ }^{74}$, un herrero de nacionalidad francesa que en aquellos momentos estaba en León, quien hacía una postura para conseguir el contrato del hierro que se iba a utilizar en la reja del cierre del atrio. Se comprometía a rebajar medio real en cada libra de material sobre el precio ajustado con anterioridad entre el herrero Juan Urrutia y el administrador de la fábrica de la catedral, lo cual

\footnotetext{
-

${ }^{73}$ Cfr. J. E. GARCía MELERO, Las catedrales góticas..., p. 119.

${ }^{74}$ El nombre de este artífice varía de unos documentos a otros, llamándole en otras ocasiones Buxtor, o Burgoa.
} 
suponía una considerable cantidad de dinero a la vista de la magnitud de la obra ${ }^{75}$. El obispo de la diócesis leonesa, enterado de la nueva oferta, interviene en el asunto y escribe una carta al cabildo catedralicio en la que solicita toda la información sobre ambas propuestas, así como el dictamen definitivo de los capitulares. Por otro lado, el prelado recuerda al cabildo el contrato previo firmado y el acreditado prestigio que tiene en su trabajo el maestro Urrutia, siendo esto de más importancia que la rebaja del precio que hacía el operario francés ${ }^{76}$.

En una nueva reunión capitular finalmente se decide rechazar la oferta del herrero francés, argumentando las siguientes razones. En primer lugar porque el nuevo postor no estaba afincado ni arraigado en León, sino que parece que se encontraba en la ciudad por casualidad. Es extranjero, por lo que estaba expuesto a ser expulsado del reino, como ya le había ocurrido a otros en las mismas circunstancias. Además se consideraba que no disponía de medios ni facultades suficientes para desempeñar una obra tan considerable, con el peligro de que la catedral podría perder el dinero que se adelantase para iniciar la obra. Por otro lado los capitulares sospechaban que había hecho la postura sin tener conocimiento exacto del plan y con una cantidad de hierro desmesurada. Por último, decían tener noticias de que en alguna obra de consideración que estaba realizando había fallado en su ejecución. Todas estas razones fueron consideradas suficientes y determinantes para desestimar la rebaja del herrero francés, creyendo honestamente que era más importante la garantía de un maestro conocido y contrastado por otras labores que el ahorro de cierta cantidad de dinero,

\footnotetext{
${ }^{75}$ ACL, Actas Capitulares, caja 444, doc. no 10.048 , fol. $132 \mathrm{v}$.

${ }^{76}$ ACL, Actas Capitulares, caja 444, doc. no 10.048 , fol. $134 \mathrm{v}$.
}

que por otra parte llegaba incluso a ser sospechosa por su excesiva rebaja ${ }^{77}$.

Es significativa la intervención episcopal en el asunto, porque demuestra que el Ilmo. Cayetano Cuadrillero estaba supervisando todos los pormenores de la obra, que recibía puntual información de los trámites y que, sin necesidad de involucrarse en las discusiones ni en las decisiones, se seguían sus preferencias; situación poco habitual, porque cabildo y obispo suelen mantener discrepancias en aquellos asuntos en los que confluyen sus competencias. Un ejemplo de la sintonía que había en aquellos momentos entre ambos lo tenemos en la resolución del contrato del hierro. El prelado se felicita porque los capitulares decidieron finalmente contratar el material con el maestro Urrutia y desechar la rebaja del maestro francés, como había sugerido con anterioridad ${ }^{78}$.

A pesar de la rotundidad de la decisión, que no daba lugar a la posibilidad de una futura revocación del fallo, el herrero Buxtorg, junto con los socios leoneses que le acompañaban en el proyecto ${ }^{79}$, hizo una nueva reclamación, esta vez ante el tribunal eclesiástico, para que se admitiera su ventajosa oferta, la cual, afirmaba, era buena para la fábrica porque le ahorraba importantes caudales $^{80}$. Tampoco esta vez fue atendida su demanda, aunque de nuevo Herrera Lorenzana y sus partidarios volvieron a protestar, pidiendo la rectificación del cabildo sobre el asunto, aunque de nada les sirvió. Una vez admitido el fallo, se acuerda dar ...parte de esta resolucion al Sr. Obispo y

\section{-}

${ }^{77}$ ACL, Actas Capitulares, caja 444, doc. n⿳o 10.048 , fols. 135 .

${ }^{78}$ ACL, Actas Capitulares, caja 444, doc. no 10.048 , fol. $138 \mathrm{r}$.

${ }^{79}$ En el documento se cita a: la viuda Manuela Manteca y su hijo y compañeros herreros de esta ciudad, ACL, Actas Capitulares, caja 444, doc. no 10.048, fol. 142 r.

${ }^{80}$ ACL, Actas Capitulares, caja 444, doc. nº 10.048, fol. $141 \mathrm{v}$ 
procediendo en todo con su acuerdo ${ }^{81}$, lo que demuestra una vez más la coincidencia de criterios que existía entre ambas instituciones, como ya vimos más arriba.

Para complicar algo más la situación, entran en escena otros herreros pretendiendo también la obra. Primero aparece el llamado Castro y Delgado, vecino de Ponferrada que tenía a su cargo la herrería de Arnado, el cual, en mayo del mismo año, solicita al administrador de la fábrica de la catedral que se le tenga en cuenta a la hora de hacer el ajuste del enrejado del atrio ${ }^{82}$.

Posteriormente, el capitular Sr. Ruiz informa que en la reciente obra de la nueva Audiencia de Cáceres, el maestro Ramón de Goicoechea, vecino de San Sebastián, fue el encargado de hacer la reja de hierro que allí se puso, con un precio del metal sensiblemente más ventajoso que el contratado con Urrutia para la reja del atrio. Razona que como León dista de Vizcaya (donde estaría la fragua) mucho menos que Cáceres, el coste del transporte del hierro sería más barato, lo que supondría un ahorro considerable; por ello propone que se haga el contrato con dicho herrero donostiarra, olvidándose tanto de la propuesta de Urrutia como de la de Buxtorg ${ }^{83}$.

Desconocemos la solución dada al conflicto, porque, después de tantas discusiones en las sesiones capitulares, recogiendo incluso detalles menores, nada se dice en las siguientes actas acerca de la resolución final adoptada. No sabemos cuando ni por qué, pero el caso es que al final se contrató la obra con un tal Goicoechea. Esto al menos es lo que se puede deducir de los

-

${ }^{81}$ ACL, Actas Capitulares, caja 444, doc. nº 10.048, fol. $143 \mathrm{v}$.

${ }^{82}$ ACL, Actas Capitulares, caja 444, doc. no 10.048 , fols. 173 v. En la documentación no consta su oferta, ni la resolución tomada por el cabildo.

${ }^{83}$ ACL, Actas Capitulares, caja 444, doc. no 10.048 , fol. 176 . datos ofrecidos en el acta capitular del 12 de mayo de 1800, cuando ya se había terminado la obra del atrio. En ella se recoge un memorial presentado por Miguel Goicoechea que solicita una gratificación por tener concluida la obra del enrejado del atrio $^{84}$. El cabildo, a la vista del informe positivo que hicieron los maestros Francisco Bibar y Juan Barela sobre la calidad de la obra y su adecuación al proyecto aprobado, decide darle la gratificación pedida, que alcanzaba la cantidad de dos mil reales ${ }^{85}$. Es muy probable que este Miguel Goicoechea esté en relación con el herrero recomendado por el Sr. Ruiz, aunque los nombres de pila no coinciden; seguramente fueran familiares que trabajaban en el mismo taller. En cualquier caso, lo que parece quedar muy claro a la vista del documento, es que a él se debe atribuir todo el trabajo de forja realizado para el atrio.

La conclusión de las obras no significó la finalización de los conflictos; al contrario, todavía surgieron nuevos problemas. En marzo de 1802 el Intendente de León, haciendo uso de las prerrogativas propias de su cargo y velando por el cumplimiento de la legalidad, exigió a la catedral el pago de un impuesto especial sobre el hierro que se había utilizado en el cierre ${ }^{86}$. Al parecer, había una orden real del ministro de Hacienda de Su Majestad por la que se establecía que todo el hierro labrado que se introdujera en Castilla y León desde provincias extrañas debía pagar un gravamen equivalente al diez por ciento de la totalidad de lo importado. Al haber traído el metal desde Vizcaya, parecía que la obligación del pago del canon era bastante clara. No obstante, el cabildo estudió con deteni-

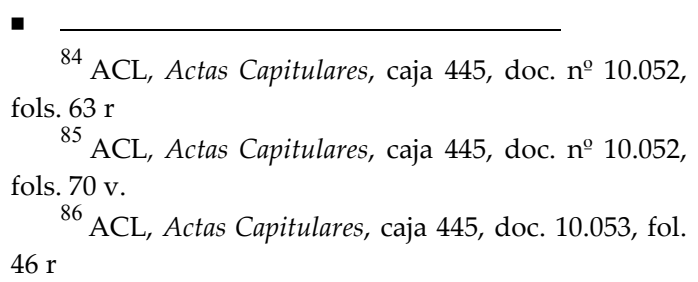
fols. $63 \mathrm{r}$

${ }^{85}$ ACL, Actas Capitulares, caja 445, doc. no 10.052 , fols. $70 \mathrm{v}$.

${ }^{86}$ ACL, Actas Capitulares, caja 445, doc. 10.053, fol. $46 \mathrm{r}$ 
miento el asunto y halló que la real Orden de 11 de octubre de 1796, en la que se basaba el Intendente para hacer su reclamación, no comprendía el caso concreto de la obra realizada en la catedral, por lo que resolvió no pagar el referido impuesto y exponer directamente ante el mismo monarca las razones que amparaban la decisión tomada por la catedral leonesa ${ }^{87}$.

\section{EL CIERRE DEL ATRIO}

La estructura del cierre del atrio que finalmente fue aprobada tiene mucho más carácter de seguridad que la primitiva; de hecho, el pretil de piedra original no tenía puertas como tales, los vanos se encontraban expeditos y era de poca alzada. Por el contrario, en la nueva configuración no sólo la altura de las vallas es mucho mayor, sino que también las puertas están pensadas para permanecer cerradas, todo ello con el fin de impedir el paso de personas y animales, aislando por completo a la catedral.

Las trazas del proyecto original, planta y alzados realizados en una única lámina de considerables dimensiones $(65 \mathrm{x}$ $98 \mathrm{cms}$.), están firmadas y rubricadas por el arquitecto Fernando Sánchez Pretejo. Aparece fechado en León el día 15 de mayo de 1794 (pocos días antes de que fuera aprobado por la Academia de San Fernando, como vimos más arriba) y tiene el siguiente título: Dibuxo que manifiesta en Planta y Alzado la forma que podra darse al Cierro del Atrio de esta Santa Yglesia Cathedral guardando los medios de las Puertas, Torres \& de la Fachada principal, y costado que mira al mediodia ${ }^{88}$. Consta de varios dibujos para explicar de la mejor manera posible el diseño del nuevo cierre, aportando tanto

\footnotetext{
${ }^{87}$ ACL, Actas Capitulares, caja 445, doc. 10.053, fol. 55.

${ }^{88} \mathrm{ACL}$, Fondo Restauración, Inventario de planos, $\mathrm{n}^{\mathrm{o}}$ 462. Fue publicado por primera vez por J. RIVERA BLANCO, Historia de las restauraciones..., pp. 155.
}

distintos aspectos de la estructura y morfología de la verja como su inserción con el edifico de la catedral, al que cercaba hasta entroncar, nada más pasar el crucero del templo, con las dependencias de la Audiencia y el Tesoro. No olvida el dibujante hacer referencia a las calles y plazas circundantes para fijar lo más exactamente posible el espacio real en el que se iba a ubicar (Lám. 6).

Por un lado se muestra en planta la dimensión total del cierre y el perfil de la planta de la catedral correspondiente a las fachadas principal y sur. En otro lugar se presenta el alzado de la verja con su total desarrollo; encima el situado en el lado oeste, formado por 14 tramos (Fachada principal del Atrio que mira al Occidente), y debajo el más largo, de 17 tramos, correspondiente al lateral sur (Fachada del Atrio a mediodia). En la esquina inferior derecha, y a escala más grande, aparece el dibujo pormenorizado de un tramo de la verja para que sirviera de ejemplo; decimos esto porque el arquitecto dibujó en él varios diseños distintos para el adorno de las rejas, que luego fueron desarrollados en diferentes lugares (Partes en grande de las figuras de balaustres y adornos que ha de llevar). A su lado está la explicación de los gruesos que debían tener tanto los balaustres, como las soleras y los adornos.

Acompañan a los dibujos diversas escalas divididas en pies castellanos, que son de distintas proporciones según el tamaño de cada diseño. En la esquina inferior izquierda una nota señala lo siguiente: $L a$ linea roja denota lo que ocupa el camape antepecho actual. Los numeros 1, los pedestales de dos estatuas; y el numero dos el arca cambija de las fuentes publicas, que se debe quitar vno y otro para dar mas ensanche al atrio, y exmra la fachada de la Yglesia.

Las estatuas a las que se refiere eran dos efigies de grandes dimensiones sobre 
pedestales, situadas en la fachada principal delante de las hornacinas que hay en los contrafuertes que marcan los extremos del pórtico, según se puede ver todavía en los mencionados dibujos de los libros de Risco y Ponz. Por lo visto, Fernando Sánchez Pertejo decidió quitarlas para dar mayor amplitud al atrio y despejar la vista de la fachada de la catedral, dos de los principales motivos de su proyecto. Las estatuas desaparecieron de su lugar y ahora se desconoce su paradero, por lo que no podemos saber su estilo ni su mérito artístico para valorar su desaparición ${ }^{89}$.

El arca que menciona está en relación con la antigua fuente que vimos situada en un extremo del atrio y con la red de distribución de aguas de la ciudad ${ }^{90}$, que tenía en aquella época la plaza de Regla un importante lugar de distribución y que fue motivo de constantes polémicas entre el cabildo y el ayuntamiento leonés ${ }^{91}$.

En cuanto al cierre, se configura mediante la alineación de pilares de base cuadrangular, todos iguales entre si, e intercolumnios cerrados con rejas artísticas de forja, diseñadas con ligeras variantes para romper la uniformidad. Esta disposición supone una sólida frontera que impide eficazmente el paso al espacio del atrio, pero al mismo tiempo es lo suficientemente transparente como para permitir contemplar sin dificultad la belleza de la catedral.

\footnotetext{
${ }^{89}$ D. DE LOS RíOS, ob. cit, t. II, p. 35, cita las estatuas $\mathrm{y}$ reconoce que nadie conoce su suerte.

${ }^{90}$ D. DE LOS RÍOS, ob. cit, t. II, p. 36, afirma que encontró en esta zona un buen número de tubos de la cañería de barro que surtía de agua a las fuentes de la ciudad.

${ }^{91}$ Sobre las conducciones de agua en la plaza de regla y las discusiones con el Ayuntamiento por las competencias sobre el tema, véase, M. D. CAMPOS SÁNCHEZ-BORdona y M. L. PEREIRAS FERnÁNDEZ, op. cit., pp. 308, 346-351.
}

Al comparar lo proyectado con lo realizado, donde observamos más diferencias es en los pilares. Siguiendo las instrucciones de la Academia que vimos más arriba, Fernández Pertejo dejó todos los frentes de los fustes lisos, desechando definitivamente las acanaladuras previstas en la traza, y presentando un capitel apenas marcado por unas finas molduras rectas. Hay en ellos un interesante juego plástico al recurrir a dos piedras de características y colores distintos; una es la típica caliza de Boñar de tono terroso, similar a la utilizada en los muros de la catedral, con la que se realizaron los fustes, mientras que para las basas y los capiteles se empleó una caliza más dura, de color grisáceo y vetas rosáceas que ayudan a animar la sencillez del conjunto.

Sobre los pilares, como estaba previsto en el plan inicial, se alternaron jarrones, florones, bolas y escudos con pequeños grupos escultóricos. Estos representan a niños semidesnudos, a modo de angelotes o putti, portando en sus manos diversos emblemas (Lám. 8). Todos están en la misma actitud pero con posturas distintas; tienen una rodilla en tierra y la otra pierna flexionada, mientras que un paño estratégicamente situado tapa sus partes pudendas. El escultor que los realizó, del que desconocemos su nombre porque no aparece citado en la documentación consultada, supo hacer una composición con un acertado juego de movimiento con los cuerpos infantiles que proporciona variedad a la serie. En la actualidad hay cinco, cifra inferior a la original y que no cuadra con el esquema del conjunto, seguramente como consecuencia de los trabajos de restauración decimonónicos. Uno de los niños lleva el escudo del cabildo, el consabido jarrón con azucenas, como referencia a la institución que encargó la obra y la que ostenta la jurisdicción en el espacio que hay tras la verja. Otro, que ahora tiene la cabeza rota y le falta el rostro, porta lo que parece ser una mitra episcopal, hoy en día muy deteriora- 
da, en alusión a la máxima autoridad de la diócesis, que también participó en la génesis de la obra y cuya sede se encuentra en la catedral. Un tercer infante muestra un cuadro donde aparece un edificio que puede sugerir, aunque el diseño sea muy tosco, a una vista de la fachada principal de la catedral leonesa. Otro señala con su dedo una escena donde aparece un équido sobre un terrero abrupto; el relieve, muy deteriorado por la erosión que ha sufrido, puede hacer referencia a una de las leyendas de San Froilán, patrono de León y protagonista de la portada meridional de la catedral, que cuenta como el santo se instaló en los montes de la Valdorria leonesa y se servía de un mulo para llevar en las alforjas los libros que leía en su vida eremítica, antes de que el lobo lo matara y ocupara su lugar por la intervención del santo ${ }^{92}$. Por último, hay un niño más que despliega una guirnalda floral que sale de un jarrón, probablemente con mero carácter decorativo.

La verja, anclada a los pedestales de piedra, tiene un diseño base común, sobre el que se hacen ligeras variaciones formales para evitar la monotonía del conjunto, a lo que contribuye también las distintas dimensiones de los tramos practicados como entradas. El esquema general es de un sólo cuerpo, sobre una base y un friso superior, estando éste coronado por una crestería de muy escaso desarrollo. Los barrotes, rectos, lisos y estilizados, son de sección cuadrada y pueden rematar sus extremos con sencillas volutas, formas curvas o alancetadas; a media altura van unidos por barras o círcu-

\footnotetext{
92 Esta leyenda no la recoge el biógrafo de San Froilán, Juan Diácono, sino que pertenece al acervo popular. J. GONZÁLEZ FERNÁNDEZ, San Froilán de León: estudio crítico-biográfico, León, 1946, pp. 78-79, señala que la leyenda se hizo popular desde el siglo XIII y se recoge en los leccionarios cistercienses y lo copiaron después los que se ocuparon de la vida del santo, por ejemplo, FRAY BERNARDO DE LA PEÑA en su obra Santos de la Orden de San Benito.
}

los para asegurar la consistencia del cierre. La estrecha franja que hace de base alterna para su adorno círculos, formas en "C" normales o invertidas, y grecas de roleos. $\mathrm{El}$ friso superior se adorna con motivos similares, aunque de mayor tamaño y desarrollo plástico. La coronación, de poca altura, queda configurada por una sinuosa y continua línea lobular. Los barrotes horizontales, que dividen las distintas alturas de la reja, sirven a su vez para sujetarla a los pilares (Lám. 9).

Los accesos para entrar en el atrio se ubican en el extremo norte, en la esquina suroeste y delante de cada una de las dos portadas catedralicias que protege; en este caso se disponen tres puertas, que se corresponden, tanto en colocación como en anchura, con las respectivas de la fachada del edificio de la catedral.

El atrio sufrió una ampliación a principios del siglo XX, aprovechando la demolición del viejo edificio del Tesoro de la catedral y el desmantelamiento de Puerta $\mathrm{Obispo}^{93}$, trabajos que despejaron este sector de la catedral. El entorno del ábside de la catedral quedó en un estado lamentable tras las obras; sin pavimentar, acumulando escombros y cascotes de las labores acometidas para abrir la muralla de la ciudad, e incluso manteniéndose todavía en pie algunas viejas y degradadas edificaciones. Para ennoblecer la zona, Juan Crisóstomo Torbado realizó en 1930 un proyecto con el fin de ampliar el atrio de la catedral en el lateral sur hasta alcanzar la sacristía ${ }^{94}$. Con

${ }^{93}$ El edificio de Puerta Obispo, que servía de entrada a la ciudad desde la época de los romanos y que en la Edad Media se le añadió una estructura superior para comunicar la catedral con el vecino palacio episcopal, fue derribado a principios del siglo XX para abrir en su lugar una calle.

${ }^{94}$ Los dibujos del proyecto se conservan en el Archivo General de la Administración (E y C), c 4.857, leg. 13.202-18, citado por I. GONZÁlEZ VARAS, op. cit., p. 487. Véase también J. RIVERA, Historia de las restaura- 
esta medida pretendía sanear la zona, pero también seguir con la intención de aislar la catedral de su entorno urbano, manteniendo la decimonónica idea de conseguir una vista franca del edificio, No se consideraba relevante la modificación del urbanismo histórico original, si ello conllevaba la pretendida exaltación del templo gótico por medio de su aislamiento del caserío circundante ${ }^{95}$.

La obra de Torbado, llevada a cabo de inmediato, consistió en seguir en línea recta el cierre de Sánchez Pretejo añadiendo 7 tramos más, imitando en todo las formas del primitivo, tanto rejas y pilares como las medidas y los escasos adornos (Lám. 10). La única diferencia se observa en la solución adoptada para salvar el desnivel del terreno, haciendo el cierre escalonado (Lám. 11).

Esta parte del cierre ha tenido otra reciente intervención. Con motivo de sacar a la luz los restos de la antigua muralla romana y la puerta ubicada en esta zona, se desmontó la obra de Torbado, se redujo la dimensión de la verja y se hizo un quiebro en el trazado del cierre para dejar espacio a los restos descubiertos. Así es como está hoy en día. ciones..., p. 156; M. D. CAMPOS SÁNCHEZ-BORDONA y M. L. PEREIRAS FERNÁNDEZ, op. cit...., pp 470-472.

${ }^{95}$ Sobre la idea de liberar a las catedrales de las edificaciones adheridas es elocuente el trabajo de L. TORRES BALBÁS, "El aislamiento de nuestras catedrales", Arquitectura, 1919, pp. 358-362, quien en su época ya alertaba sobre los peligros derivados del aislamiento, tanto en aspectos estéticos, como de significado o escala, así como por la pérdida documental derivada de la eliminación de los vestigios del pasado. 


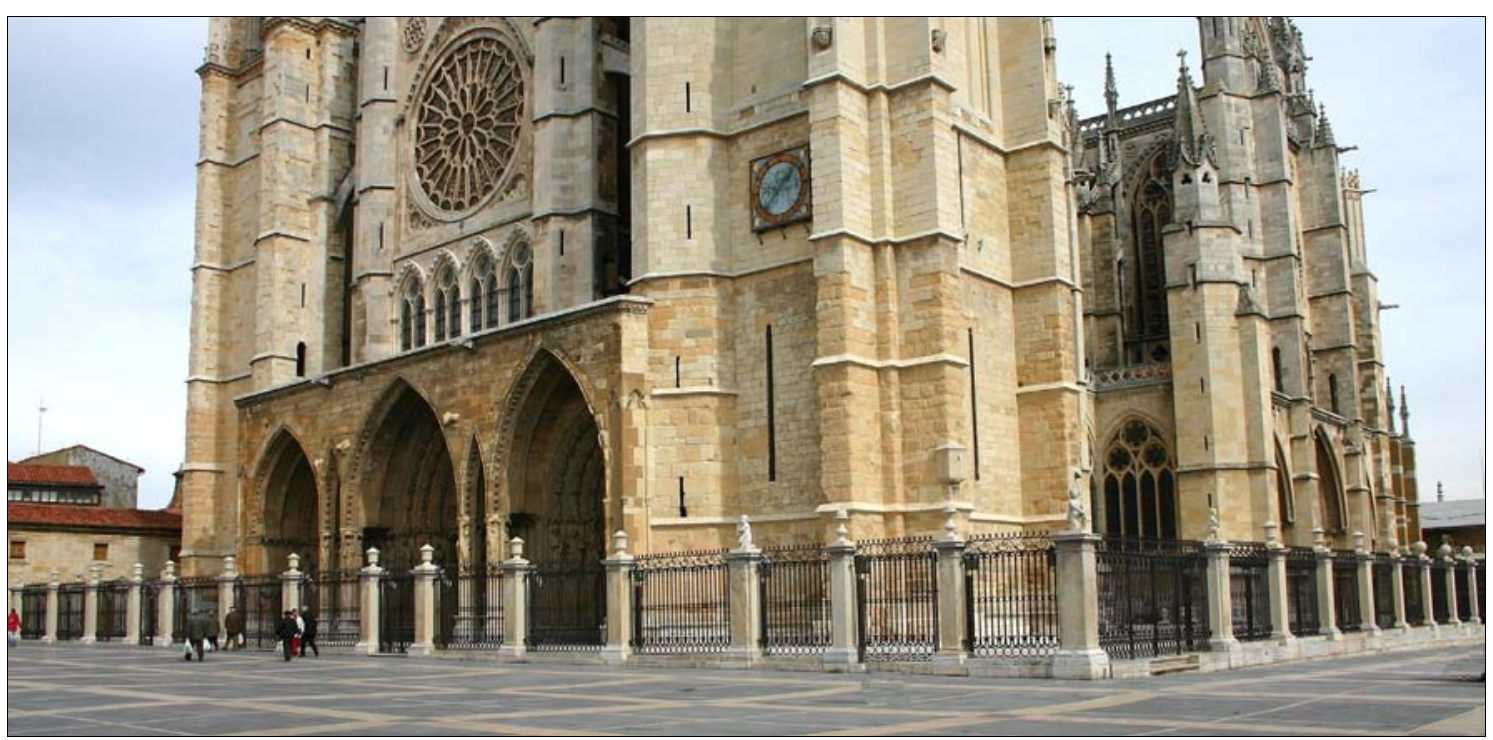

- Lám. 1. Vista actual del atrio de la catedral (foto del autor).

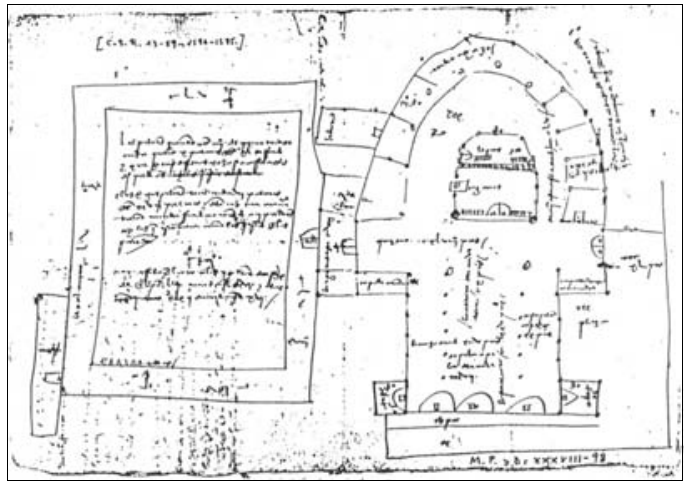

- Lám. 2. Dibujo de la planta de la catedral de León de 1514. (AGS, Mapas, Planos y Diseños, XXXVIII- 98 Casas y Sitios Reales, leg. 13, fol. $59)$.

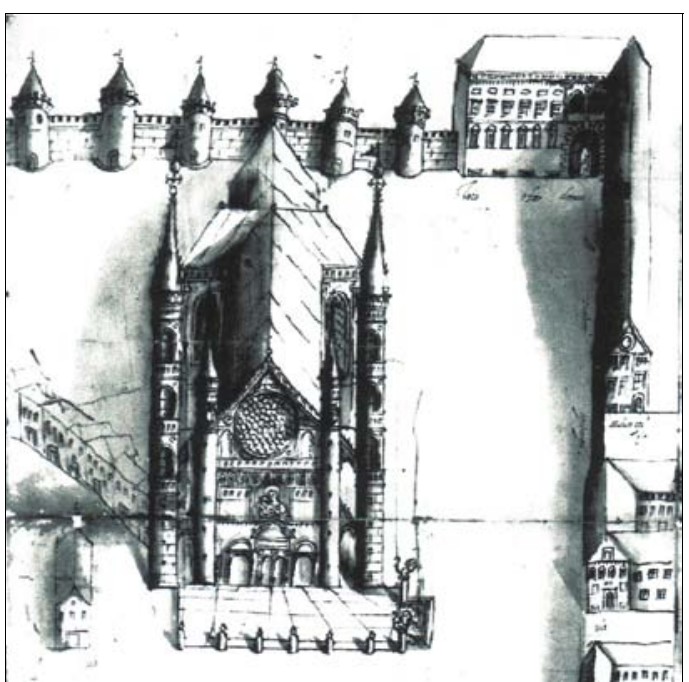

- Lám. 3. Detalle de un dibujo de la catedral de León de finales del siglo XVI. (ACL, Dibujos, letra f, leg. 4). 


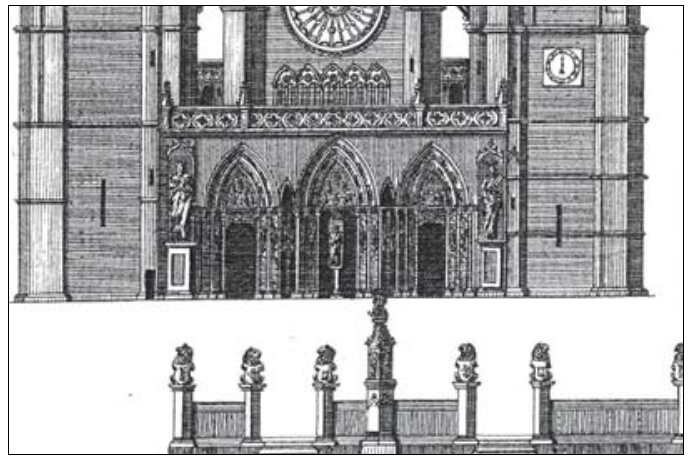

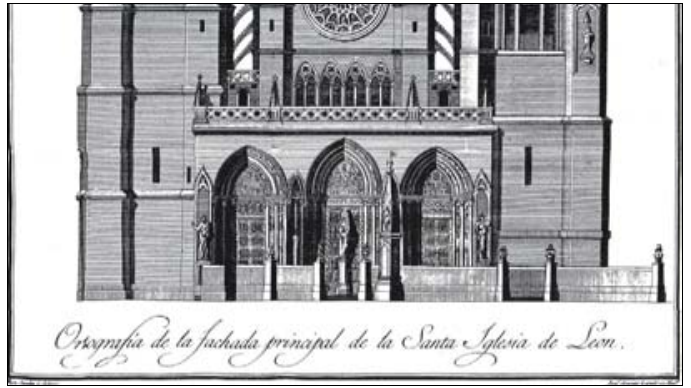

- Lám. 4. Detalles de los dibujos de Fernando Sánchez Pertejo (M. Risco) y del incluido en la obra de Antonio Ponz, Viage de España, t. XI, Madrid, 1787.

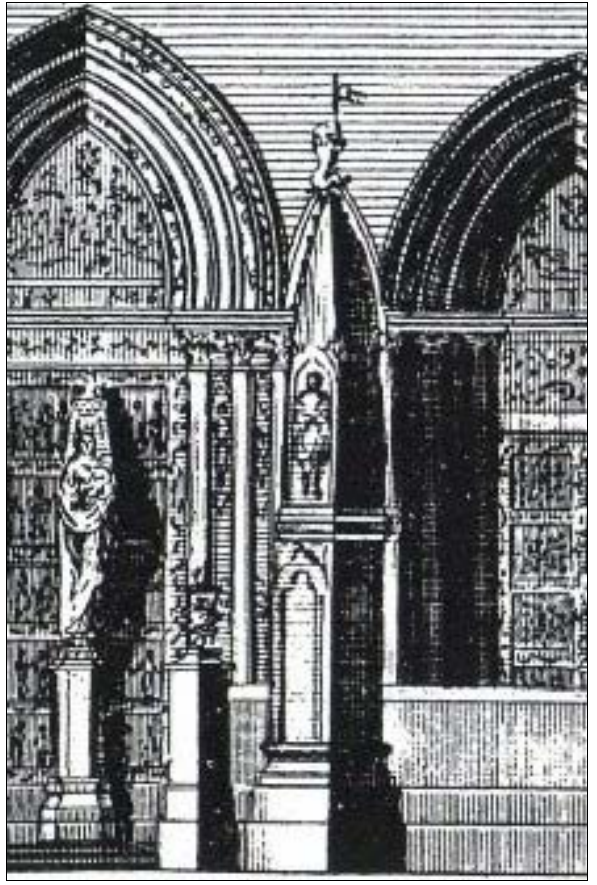

- Lám. 5. Detalle del dibujo de F. Sánchez Pertejo (M. Risco) en el que se ve el pilar.

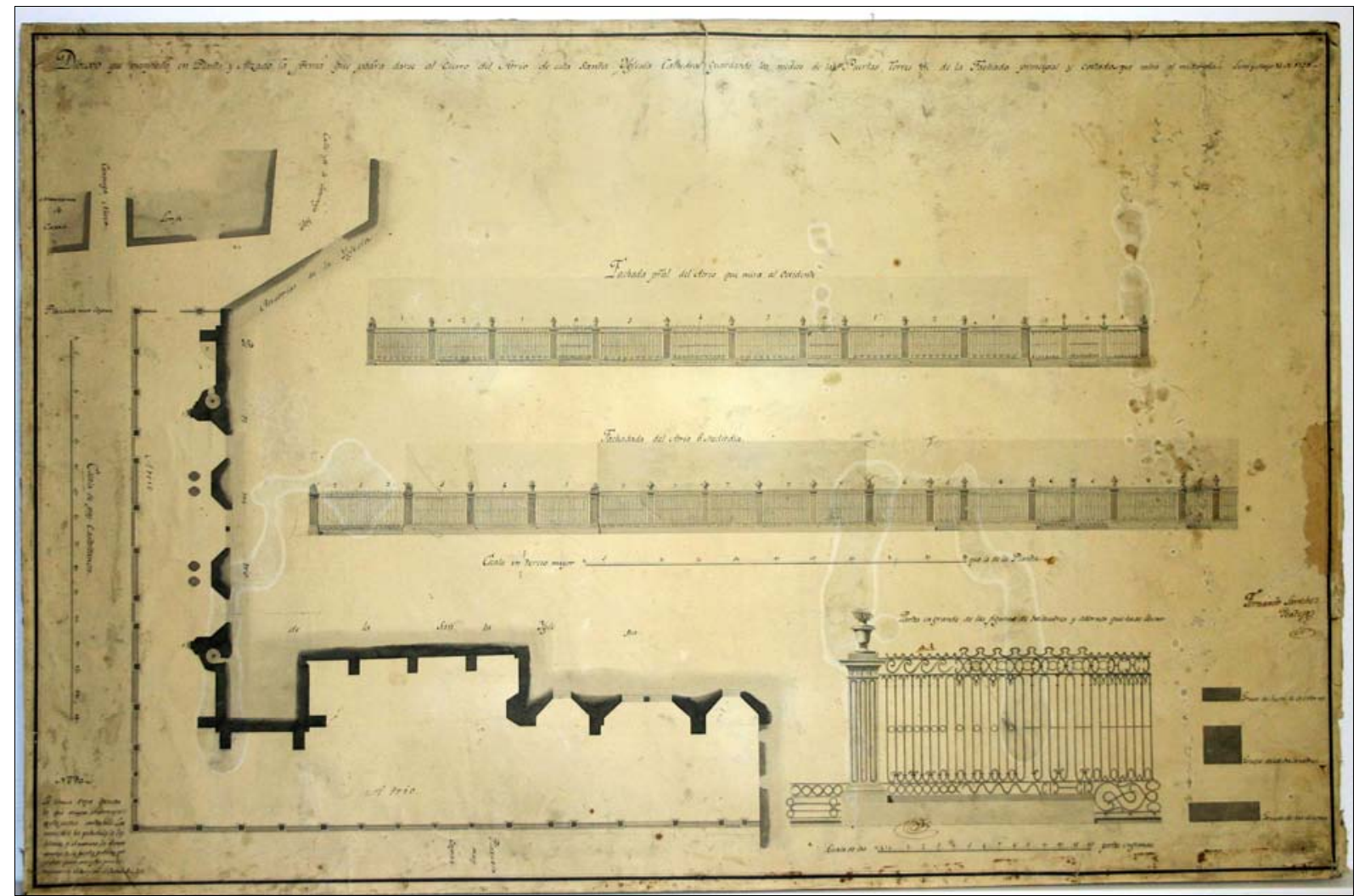

- Lám. 6. Proyecto de Fernando Sánchez Pertejo para hacer el cierre del atrio. (ACL, Fondo Restauración, Inventario de planos, $\mathrm{n}^{\mathrm{0}} 462$ ). 


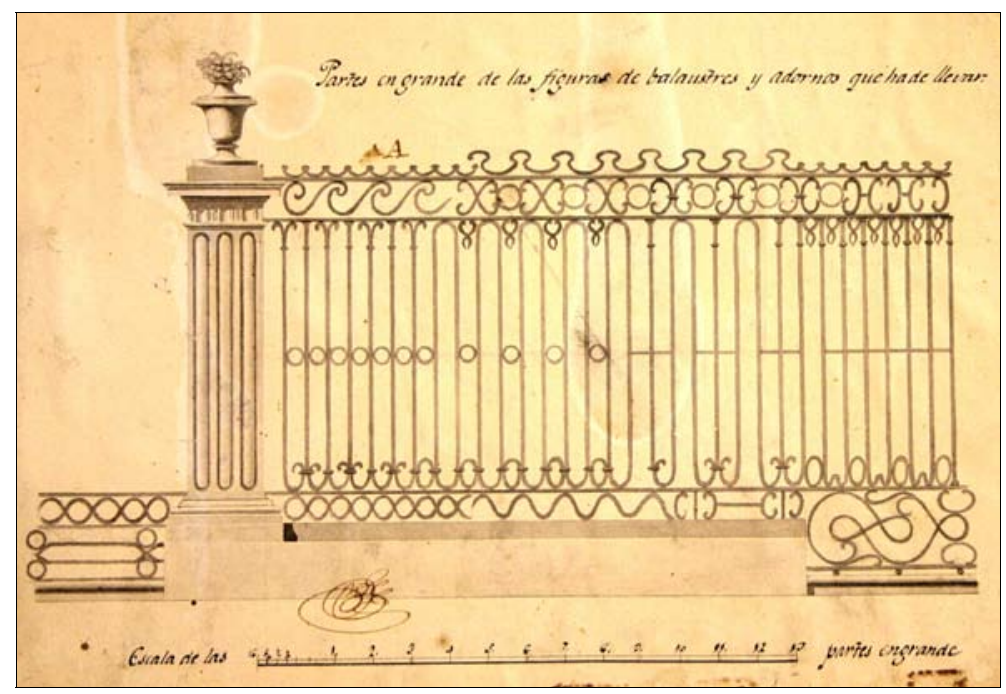

- Lám. 7. Detalle del proyecto de Fernando Sánchez Pertejo donde se aprecia el diseño de las rejas. (ACL, Fondo Restauración, Inventario de planos, $\mathrm{n}^{\mathrm{o}} 462$ ).

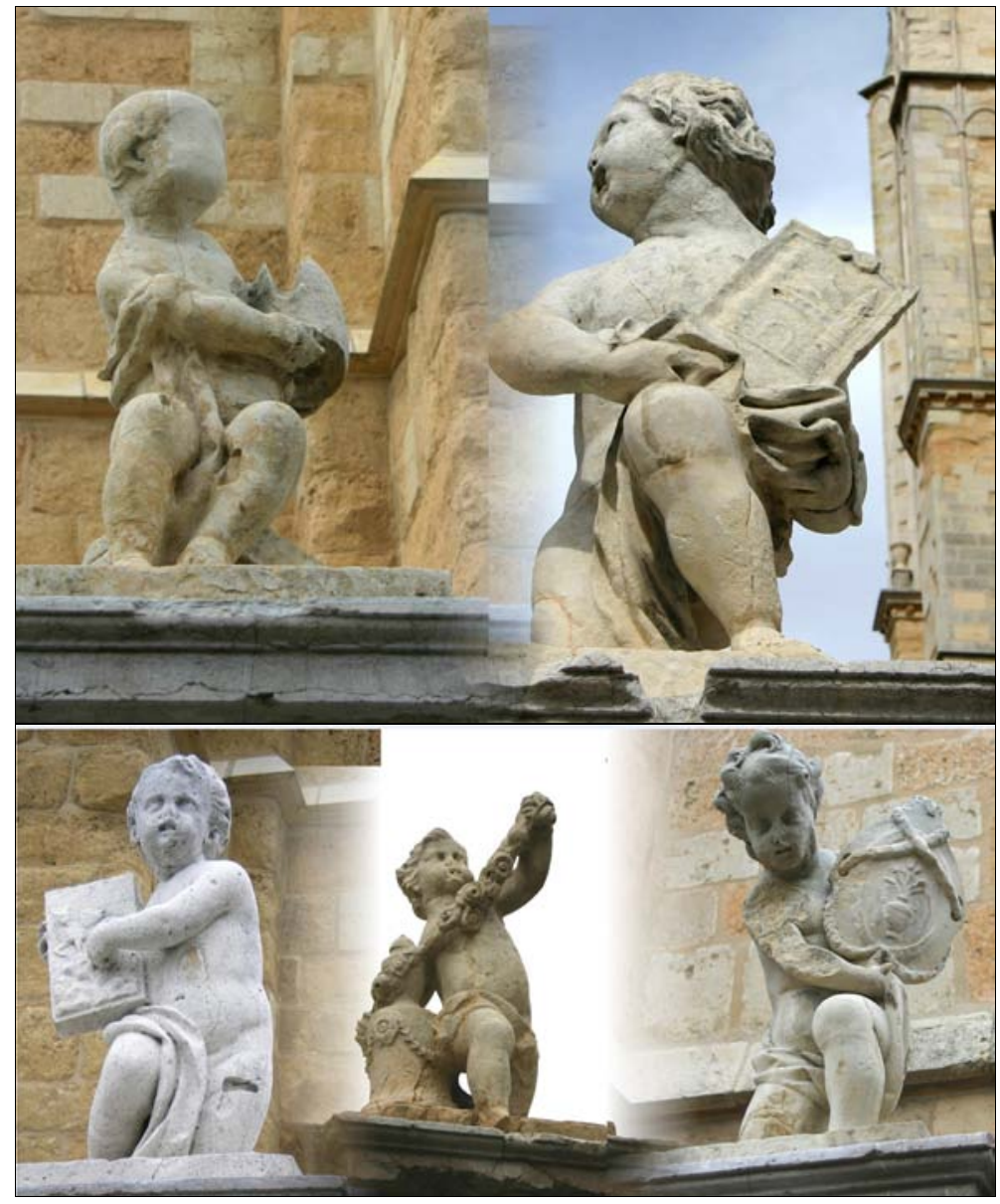

- Lám. 8. Detalle de las esculturas que coronan los pilares del cierre (foto del autor). 

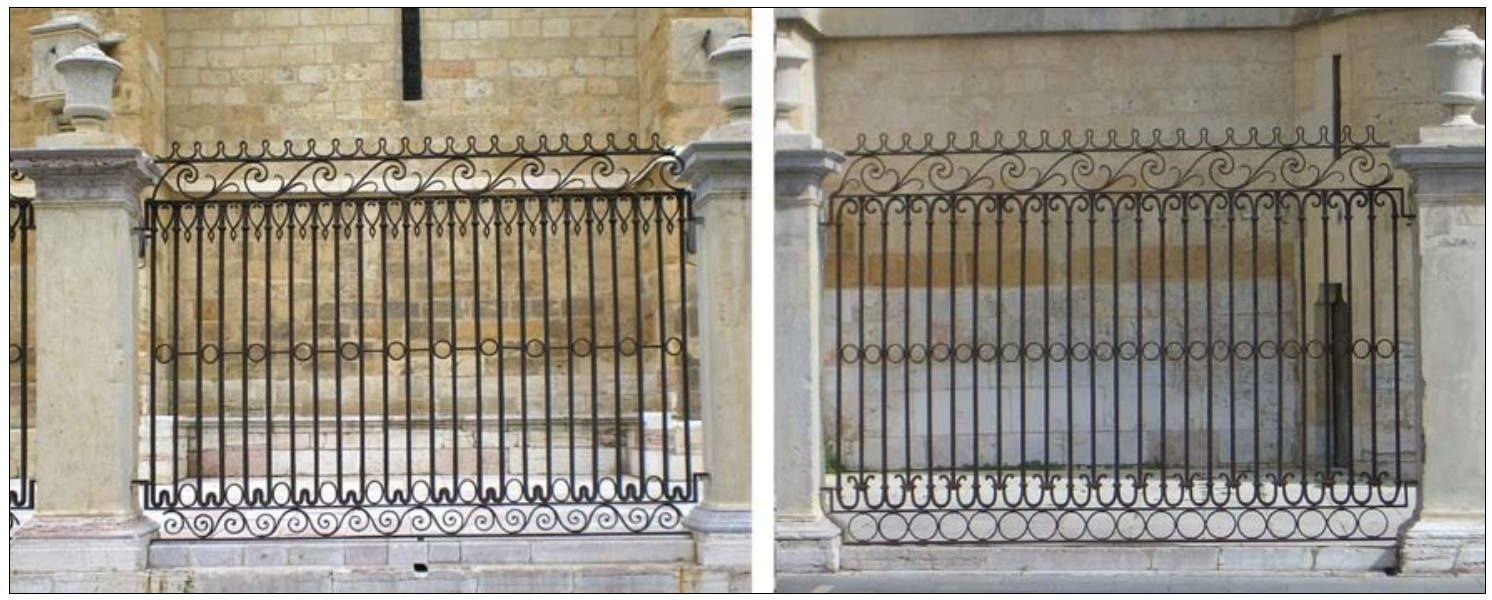

- Lám. 9. Dos tramos del cierre del atrio en la actualidad, con ligeras variaciones en el diseño (foto del autor).

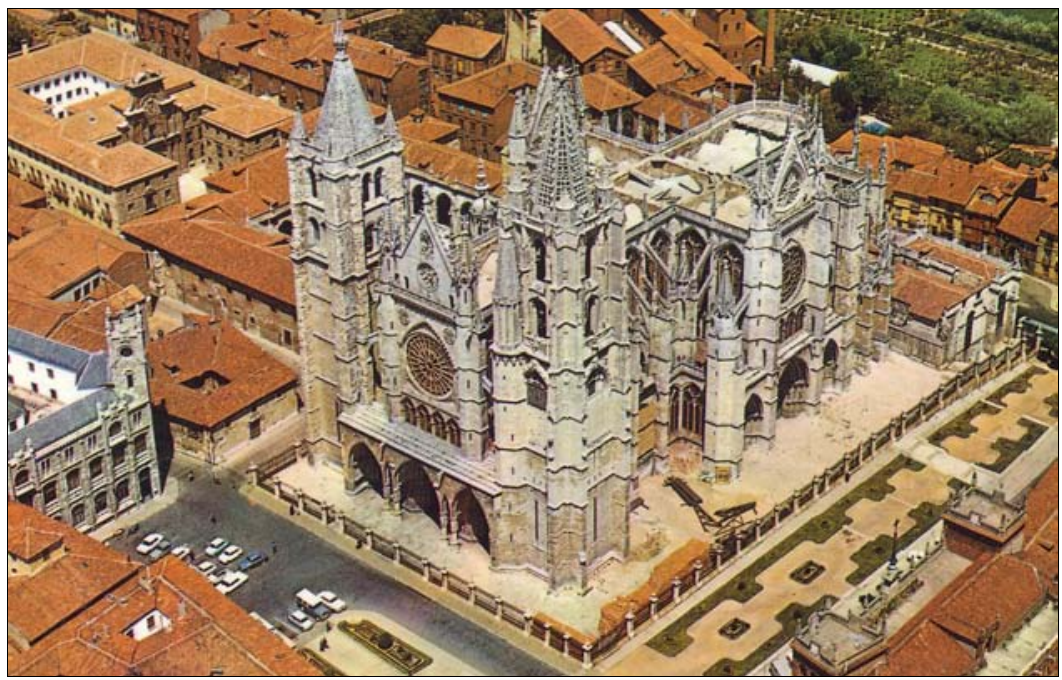

- Lám. 10. Vista aérea de la catedral en la que se puede ver el atrio según quedó tras la ampliación de J. C. Torbado. (Fondo del ILC).

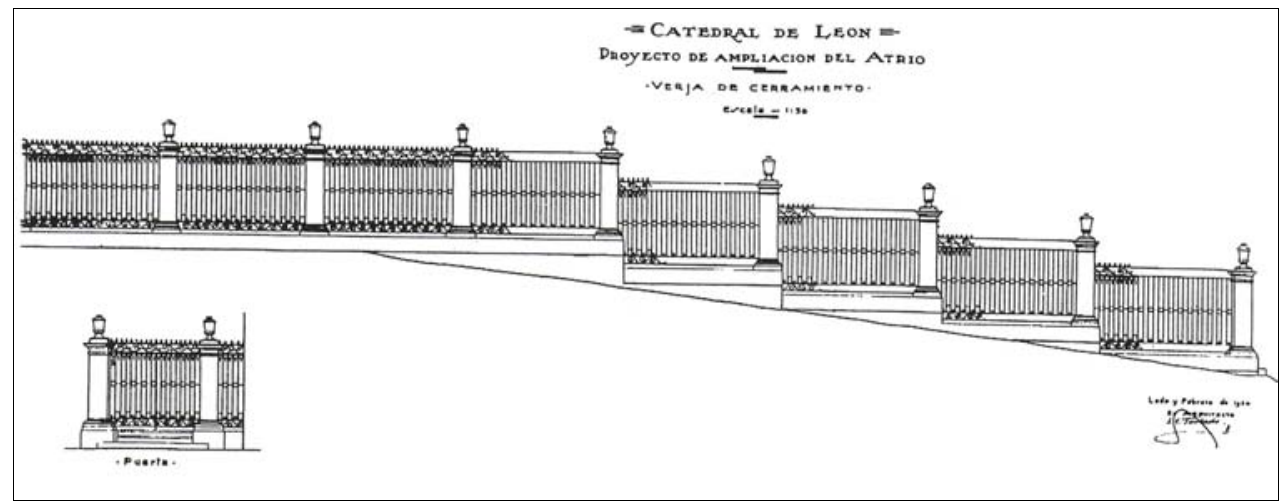

- Lám. 11. Proyecto de ampliación del atrio realizado por J. C. Torbado, (Archivo General de la Administración (E y C), c. 4.857, leg. 13.202-18). 